\title{
Modelling transport emissions in an uncertain future: What actions make a difference?
}

\author{
Matteo Craglia*, Jonathan Cullen
}

2020

\begin{abstract}
A range of technology and policy actions can be put in place to reduce carbon emissions from passenger cars, this paper aims to prioritise between them, based on their likely impact and uncertainty. Formal sensitivity analysis techniques are used for the first time to determine the relative importance of factors affecting future emissions from passenger vehicles in Great Britain.

The two most important actions to limit future life-cycle $\mathrm{CO}_{2}$ emissions involve shifting to electric vehicles and limiting trends towards larger and more powerful vehicles. According to our analysis over $80 \%$ of the uncertainty in future cumulative $\mathrm{CO}_{2}$ emissions can be attributed to uncertainty in electric vehicle uptake and vehicle size and power. These variables are a priority for transport policy makers. The analysis also highlights variables of comparatively low importance; these include the share of HEVs, the Rebound Effect and the utilisation factor of PHEVs.
\end{abstract}

\section{Introduction}

Scenario analysis has become a popular tool to investigate future transport emissions and to help inform policy measures. Scenarios of future transport emissions are typically guided by a numerical model, which draws in a series of input variables (such as the share of electric vehicles in the future, the prevalence of biofuels, the efficiency of future vehicles) and computes an estimate of future energy use or $\mathrm{CO}_{2}$ emissions. Scenarios are defined by choosing a set of values for each input variable. This is generally structured in the form of 'what if' research questions, which allow the researcher to compare different possible futures to each other. Scenario analysis can be useful for policy appraisal to understand the possible effects that different actions or policy targets may have on future emissions.

Whilst informative, scenario analyses are often hampered by the uncertainty of the future, meaning subjective assumptions of input variables, such as technology uptakes, often struggle to pass the test of time. Scenario analyses are often used to compare the relative importance of different policy measures. However, this can be challenging when there are a large number of input variables and multiple interactions between them. The relative importance of stimulating the uptake of electric vehicles, for example, is dependent upon the share of electric vehicles in the fleet, the emissions intensity of electricity and the emissions produced by alternative vehicle technologies. Uncertainty in any of the latter variables may change the relative importance of policy measures.

${ }^{*}$ Corresponding Author, Email: mamc4@cam.ac.uk, Address: University of Cambridge, Trumpington Street, Cambridge, CB2 1PZ, UK 
In this paper we study future transport emissions in Great Britain and ask the question 'what makes a difference?' To account for the uncertainty in the future and the complex interactions between variables that govern estimating transport emissions, we introduce a method from the field of sensitivity analysis to the modelling of future transport emissions for the first time. This method allows for the plethora of possible model input variables to be ranked by their relative importance. This prioritisation of efforts can help to both support policy-making, as well as aiding researchers identify the most sensitive and important variables to consider in future work.

The next section presents an overview of existing methods to estimate future transport emissions and follows with a description of sensitivity analysis techniques. Section 3 then describes the model developed in this paper, with the main results presented in section 4 and summarised in section 5 ,

\section{Estimating future transport emissions}

\subsection{Scenario analysis}

Scenario analyses of future transport $\mathrm{CO}_{2}$ emissions now exist for most major vehicle markets. Studies can generally be grouped by the various points of academic interest that they share. Some have focused mostly upon a projection of 'business-as-usual' emissions (Daly and O Gallachoir, 2011). Numerous studies investigate different scenarios of technology uptake of vehicle powertrains and low-carbon fuels and compare these to a business-as-usual scenario (Singh and Strømman, 2013; Reichmuth et al., 2013; Nocera and Cavallaro, 2016; Melaina and Webster, 2011; Baptista et al., 2012; Bodek and Heywood, 2008).

Fewer papers compare technology uptake policies to other measures involving demand reduction and modal shift, though the latter are increasingly seen as an essential measure of many decarbonised futures (Brand et al., 2013; Brand, 2016; Brand et al., 2019; McCollum and Yang, 2009). The importance of modal shift and demand reduction policies is further accentuated when life-cycle impacts from embodied emissions in materials are considered (Garcia and Freire, 2017). Several papers have focused on the life-cycle aspects of future transport emissions models (Cheah et al., 2009; Kagawa et al., 2013; Pauliuk et al., 2012; Knobloch et al., 2020), with some placing particular emphasis on the potential for vehicle light-weighting (Bandivadekar et al., 2008; González Palencia et al., 2012; Garcia et al., 2015) and material substitution (Modaresi et al., 2014: Serrenho et al., 2017).

Many authors stress that scenarios are not to be considered forecasts of the future but rather possible futures (IEA, 2018; Brand et al., 2019). To create each scenario, several permutations of assumptions for input variables are required. The choices regarding input variables, from the carbon intensity of energy sources, to the uptake of different vehicle technologies, life-cycle factors, future travel demand and the size of vehicles demanded, can have large impacts upon the scenario. Even the best assumptions of input variables are subjective, and often fail to pass the test of time. A scenario remains useful if it covers a possible and actionable future. When this is no longer the case, due to outdated assumptions, the scenario becomes less relevant.

Bodek and Heywood (2008) for example develop fleet models for European countries and produce scenarios for the 2005-2035 period, yet no electric vehicles are considered, as the authors 'do not expect them to account for a significant fraction of new vehicle sales (e.g. equal to or greater than 5 percent) in Europe by 2035'. Baptista et al. (2012) compare 5 different technology scenarios for Portugal, but with a high high electric vehicle (EV) uptake scenario which conservatively assumes $20 \%$ new car sales in 2050. These assumptions may have been considered reasonable at the time of their publication, and seem conservative only with the benefit of hindsight. The latest Electric Vehicle Outlook published by the IEA (2019) 
estimates that EVs will account for $26 \%$ of new car sales in Europe by 2030 in their conservative New Policies Scenario, and almost $50 \%$ in their high ambition scenario. History may, in turn, prove these latter estimates to be overly ambitious, or excessively conservative. However, these examples serve to highlight the dependence of scenarios on the values of input variables selected by modellers.

In addition to difficulties dealing with future uncertainty, a further challenge with scenario analyses is assessing the relative importance of individual input variables, when several choices have had to be made in each scenario. Common methods to assess a variables' importance involve choosing a selection of values (e.g. different sales shares of EVs), whilst holding all other variables constant. However, this becomes increasingly challenging as the number of variables inputted into the model increases, and as variables interact/are not independent. This can make it difficult to know which variables to prioritise and investigate in greater depth and raises the question 'which are the most important variables to consider'? To paraphrase Prof. Art B. Owen: 'Unimportance is important as it lets you focus on the key inputs. Often most variables are unimportant, and they cannot all be relatively important' (Owen, 2016).

\subsection{Stochastic methods to account for uncertainty}

Rather than focusing on a limited set of deterministic scenarios, stochastic methods can be used to consider a range of scenarios given uncertainty ranges in each of the input variables. Stochastic analyses use Monte Carlo techniques to obtain likely ranges of future emissions (Bastani et al., 2012; Martin et al., 2015; Onat et al., 2016) and are useful for defining a future solution space, from which the probability of any given outcome can be gauged. All future looking analyses are inevitably dependent upon the input variables used. Conservative estimates of the uptake of a particular low-carbon technology will produce conservative estimates of its potential to reduce future carbon emissions. The benefit of using stochastic methods over deterministic scenario analysis is that they define a range for each input parameter rather than a single arbitrary value. This requires specifying upper and lower bounds for each input variable, forcing the modeller to question the future potential of each variable and account for its uncertainty.

Using Monte Carlo methods to define the uncertainty in future emissions pathways is important for assessing the feasibility of policy proposals. It can also be useful to examine the likelihood of attaining a desired result; this is known as 'Uncertainty Analysis' and serves to answer the question 'how uncertain is this inference?' (Saltelli and Annoni, 2010). Uncertainty analysis can be coupled with 'Sensitivity Analysis' which asks the complementary questions: 'what input variables define the given uncertainty?' and 'what is their relative importance?' Sensitivity analysis is used for a variety of purposes from understanding a model's behaviour and calibration, to supporting decision making by prioritising actions based on uncertainty (Pianosi et al., 2016).

\subsection{Sensitivity Analysis}

In many modelling studies, the influence of input variables are investigated by changing their values one-at-a-time (OAT analysis) and observing the change in the output. However, this method is compromised if there are interactions and dependencies between variables (Saltelli and Annoni, 2010). For example, the emissions impact of a $10 \%$ increase in electric vehicles is dependent on other variables such as the assumed carbon intensity of grid electricity and the size of vehicles.

Regression techniques can be used as an alternative sensitivity analysis method to OAT analysis. A vehicle stock model may be expressed as a function $f$ that maps $k$ inputs $X_{i}$ (such 
as uptake of electric vehicles, rate of future efficiency improvements...), to produce an output $Y$ (e.g. annual life-cycle emissions) as shown in equation 1 .

$$
Y=f\left(X_{1}, X_{2}, \ldots X_{k}\right)
$$

Function $f$ can be approximated as a linear statistical model given by equation 2 or a variation thereof (for example including quadratic terms or some interactions between variables).

$$
\hat{Y}=\beta_{1} X_{1}+\beta_{2} X_{2}+\ldots+\beta_{k} X_{k}
$$

The coefficients $\beta_{i}$ can be estimated using regression techniques and give a measure of the effect that a change in a model input $X_{i}$ may have on the output $Y$, holding all else equal. This is the approach taken by Bastani et al. (2012), who use Monte Carlo methods with a stock model of vehicles in order to produce a range of estimates of future $\mathrm{CO}_{2}$ emissions from transport. To investigate the importance of model input variables, the authors estimate a statistical model of the form of equation 2 to approximate the stock model. The coefficients $\beta_{i}$ are then used to measure the sensitivity of the output variables to a unit change in a given input variable.

Using the correlation coefficients $\beta_{i}$ as measures of importance is useful in its simplicity and ease of interpretation. However, it suffers two main limitations. The first is that it doesn't account for variance that may be present in the input variables. Two inputs may have the same magnitude correlation coefficient (meaning a unit change in either would have the same impact upon the model output), but the first input may have much higher variance/uncertainty than the second, making its effect more important upon the uncertainty in the model results. This limitation can be addressed using standardized regression coefficients (SRCs) (Monod et al., 2006) shown in equation 3 . These scale the correlation coefficient of an input variable $X_{i}$, by its variance $s_{i}$ divided by the variance of the output $s_{\hat{Y}}$. Using SRCs therefore normalizes the regression coefficients by the variances of the model variables giving a better measure of the 'importance' of different variables.

$$
\hat{\beta}_{i, \mathrm{SRC}}=\hat{\beta}_{i}\left(s_{i} / s_{\hat{Y}}\right)
$$

However, SRCs still suffer from a second limitation as they are dependent upon the statistical validity of the regression model (eqn. 2) used to approximate the model output values (Pianosi et al., 2016). In practice, it is difficult to account for non-linear relationships and interactions between variables, meaning higher order effects might be omitted.

To address both of these limitations, an alternative method, first proposed by Sobol (2001), can be used to quantify the importance of different input variables. This method decomposes the variance in the output of a model, to calculate a 'sensitivity index' for each input. Furthermore, it acts upon the variance of the output directly, without requiring an intermediate regression model (such as eqn. 22) to approximate the output results (Monod et al., 2006). This has the advantage that the model can be treated as a 'black box' and can account for interactions between variables, thereby addressing the main limitations of regression and OAT methods.

Sobol indices have been used in a wide range of fields, from estimating the relative importance of different sources of radiative forcing on climate change (Smith et al., 2019), to building energy analysis (Wei, 2013), railway design (Quaglietta and Punzo, 2013) and crop yield predictions (Monod et al., 2006). However, Sobol indices have yet to be applied in the study of future emissions from the transport sector.

This paper explores the likely range of possible futures for the passenger vehicle fleet in the UK, quantifying the $\mathrm{CO}_{2}$ emissions in each using a vehicle stock model. Sobol sensitivity analysis is then used to rank the importance of input variables on future transport $\mathrm{CO}_{2}$ emissions for the first time. This novel method can evaluate the relative importance of input variables and thereby help to prioritize interventions to reduce emissions. 


\section{Methods}

Future carbon emissions from passenger cars are determined by the current and future stock of vehicles on the road. These can be estimated using numerical models that predict the turnover of the vehicle stock (via new car sales and scrappage of old vehicles) and the emissions intensities of constituent vehicles. The input variables to vehicle stock models can change the predicted number of vehicles on the road and the emissions they generate. The sensitivity of future emissions projections to each input variable can be assessed using Sobol indices, described in section 3.1. The equations governing the structure of the stock model and the forecasting of carbon emissions from vehicles is explained in section 3.2. Finally, the variance/uncertainty of important, user-defined input variables in the stock model are discussed in section 3.3 .

\subsection{Sobol Indices}

Sobol indices are used to decompose the variance of an output $Y$, due to various model inputs $X_{i}$. 'If a particular input variable $X_{i}$ were set to a certain defined value $x_{i}^{*}$, how might that change the output $Y$ ?' The expected values of the output $Y$ from setting $X_{i}$ to $x_{i}^{*}$ can be written as:

$$
E_{X_{\sim i}}\left(Y \mid X_{i}=x_{i}^{*}\right)
$$

These are the range of $Y$ output values obtained by changing all variables to all of their possible values but holding the $i$ th variable constant at $X_{i}=x_{i}^{*}$. The $X_{\sim i}$ subscript denotes that the set of values are calculated across all input variables besides the $i$ th. If we now calculate the variance of this value, for every possible value of $X_{i}$ we get:

$$
V_{X_{i}}\left(E_{X_{\sim i}}\left(Y \mid X_{i}\right)\right)
$$

This term can be interpreted as the variance in the output of the model that is dependent upon input variable $X_{i}$. The total variance of $Y$ can be decomposed into two terms:

$$
V(Y)=\underbrace{V_{X_{i}}\left(E_{X_{\sim i}}\left(Y \mid X_{i}\right)\right)}_{\text {Variance from } X_{i}}+\underbrace{E_{X_{i}}\left(V_{X_{\sim i}}\left(Y \mid X_{i}\right)\right)}_{\text {Residual variance }}
$$

The second term in equation 4 is known as the residual (Saltelli et al., 2010) and describes the variance in $Y$ that is independent of $X_{i}$. If the input variable $X_{i}$ has a large effect on the variance of $Y$ then the first term in equation 4 will be relatively large. Sobol (2001) proposed a measure of sensitivity $S_{i}$, as the ratio between the variance explained by variable $X_{i}$ and the total output variance $V(Y)$ :

$$
S_{i}=\frac{V_{X_{i}}\left(E_{X_{\sim}}\left(Y \mid X_{i}\right)\right)}{V(Y)}
$$

The closer $S_{i}$ is to 1 , the more important the variable $X_{i}$ is at explaining the variance in the output $Y\left(S_{i} \leq 1\right)$. Interactions between variables can add to their importance. To account for this, Sobol (2001) developed the following decomposition, which sums the Sobol indices of all possible parameter interactions:

$$
\sum_{i=1}^{k} S_{i}+\sum_{i=1}^{k} \sum_{j>i} S_{i j}+\ldots+S_{12 \ldots k}=1
$$

The first term is the same as that in equation 5 and defines the share of output variance $V(Y)$ due to input $X_{i}$. Subsequent terms denote the share of output variance $V(Y)$ due to 
combinations of input variables e.g. $X_{i}$ and $X_{j}$. The cumulative effect that an input variable $X_{i}$ has upon $V(Y)$, accounting for all interactions, is therefore the sum of all terms in equation 6 with subscript $i$. Calculating all of the terms in equation 6 can be labour/computationally expensive. To address this challenge, Homma and Saltelli (1996) proposed a similar, widely used sensitivity metric, called the 'total effect Sobol index' $S_{T i}$, which accounts for all higher order interactions between variables.

$$
S_{T i}=\frac{E_{X_{\sim i}}\left(V_{X_{i}}\left(Y \mid X_{\sim i}\right)\right)}{V(Y)}=1-\frac{V_{X_{\sim i}}\left(E_{X_{i}}\left(Y \mid X_{\sim i}\right)\right)}{V(Y)}
$$

Empirically, both Sobol indices are estimated using Monte Carlo methods. Each variable $X_{i}$ is set to a random value $x_{i}^{*}$ from a given distribution and the function $f$ is evaluated to give an output $Y$, holding all other variables $X_{\sim i}$ constant. This is performed iteratively until all the parameters in equations 5 and 7 can be determined.

The present work uses 'total effect Sobol indices' $S_{T i}$ to capture all interactions between variables, thereby addressing the main limitations of regression and OAT methods. Sobol indices are calculated for each input variable in order to determine its relative importance on the future of transport emissions. Knowledge of the relative importance of variables aids in the prioritisation of actions to reduce emissions by accounting for uncertainty. The range of input variables and the structure of the stock model used to estimate future transport emissions are detailed in the next section.

\subsection{Building a vehicle stock model for Great Britain}

This analysis focuses on light-duty passenger vehicles. This section will firstly describe how the turnover of the fleet is modelled. Next, the methods used to predict future travel demand are detailed. Subsequent sections explain how the fuel efficiency of new vehicles is estimated and how these are incorporated into estimates of total $\mathrm{CO}_{2}$ emissions from British vehicles each year.

\subsubsection{Model Structure}

Figure 1 shows the composition of the model. Exogenously defined, stochastic input variables are iteratively fed into the model giving a range of $\mathrm{CO}_{2}$ emissions estimates for different combinations of input parameters. The equations that govern the model are explained in the following section. 
Travel Demand module

Car mode share
Population Car pkm
Pkm/capita Car vkm
Load factor

Powertrain Shares module

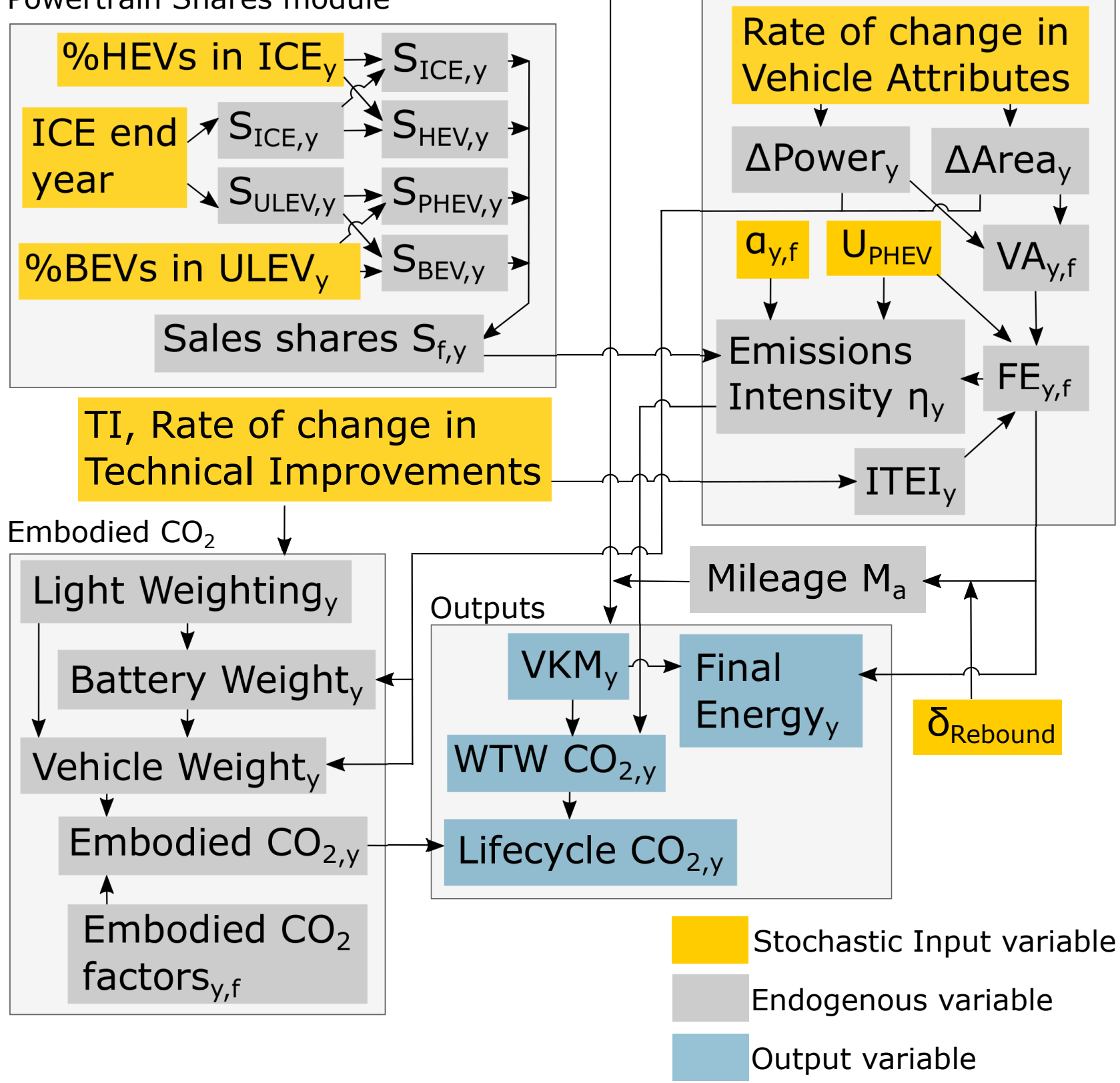

Figure 1: Flow chart of emissions model. Input variables are introduced stochastically producing a range of outputs.

\subsubsection{Modelling fleet turnover}

Estimates of vehicle scrappage rates are generally not publicly available and require creating a stock model to estimate the age distribution of vehicles on the road. Vehicle stock models 
have been used in past work (Brand, 2010; Martin et al., 2017, Serrenho et al., 2017) and generally require knowledge of the age of vehicles in a given base year (DfT, 2019c). This information can be used with new vehicle registrations data (DfT, 2019d) to determine curves which describe the probability of scrappage as a function of vehicle age. These curves generally take the form of a modified Weibull distribution as first proposed Romanowicz and Owsiński (1988) and subsequently built upon by Zachariadis et al. (1995):

$$
\phi_{a}=\exp \left[-\left(\frac{a+b}{T}\right)^{b}\right]
$$

where $a$ is the vehicle age in years, $\phi_{a}$ is the share of vehicles of age $a$ that are still on the road, $b$ is the failure steepness of the curve and $T$ is the characteristic service life. This curve can be used to determine the probability $\gamma$ that a vehicle of age $a$ is still registered on the road:

$$
\gamma_{a}=\phi_{a} / \phi_{a-1}
$$

The number of registered vehicles $V$ of age $a$ in a given year $y$ can therefore be calculated with knowledge of the number of registered vehicles in the previous year according to:

$$
V_{y, a}=V_{y-1, a-1} \times \gamma_{a}
$$

The total number of vehicles leaving the stock as scrap in any given year is calculated from:

$$
\operatorname{Scrap}_{y}=\sum_{a} V_{y-1, a-1} \times\left(1-\gamma_{a}\right)
$$

In the present work, $\phi_{a}$ (and consequently the expected vehicle lifetime) is assumed constant over time, in line with past literature (set at 2018 values $T=22.5, \mathrm{~b}=6.5$ determined using registration data from $(\mathrm{DfT}, 2019 \mathrm{c})$ ). This is a simplification, as the characteristic lifetime $T$ of vehicles has been increasing slowly over time (Dunant et al., 2020). However, including a dynamic $\phi_{y, a}$ greatly increases the computational burden of running a stock model (as the stock needs to be recalculated in each model run), which is impractical when using the Monte Carlo based methods required to produce Sobol indices. This means changes to the lifetime of vehicles (e.g. via scrappage schemes or vehicle manufacturer design changes) are not considered.

\subsubsection{Modelling future travel demand}

Demand for passenger miles travelled (PMT) per capita is initially assumed to remain constant into the future; meaning total demand for PMT increases proportionately to population forecasts sourced from the ONS (2019). This assumption is then changed in section 4.6. The share of PMT by car is an exogenous input into the model with a range of uncertainty into the future. Vehicle occupancy data from the DfT (2019a) is used to calculate total demand for vehicle miles travelled by car (VMT) in every year. This is divided by average vehicle mileage $M$ to calculate $V_{y}$ the total number of vehicles required in any given year $y$ to satisfy travel demand.

The stock model iteratively determines the vehicles scrapped each year. The annual number of new vehicles is calculated according to equation 12 , which ensures there are adequate numbers of new vehicles to satisfy demand. The implication of this model structure is that modal shift assumptions affect the choice of when to purchase a vehicle rather than changing the mileage of existing vehicles.

$$
\text { New } \operatorname{cars}_{y}=\left(V_{y}-V_{y-1}\right)+\operatorname{Scrap}_{y}
$$


The present analysis refrains from explicitly estimating the effect that future fuel prices or future GDP trajectories could have on travel demand; instead a range of future travel demand is investigated in section 4.6. However, the influence that fuel efficiency improvements (which reduce the cost of driving) may have on stimulating greater mileage is included. This effect, known as the rebound effect, is calculated each year based on the change in the average fuel consumption of the vehicle stock and is included into the model in a similar fashion to Daly and O Gallachoir (2011). The prices of fuel and electricity are assumed to remain constant at 2018 levels (fuel $\approx £ 1.3 / \mathrm{L}$, electricity $\approx £ 0.12 / \mathrm{kWh}$ ). These are used to determine the energy cost of driving $P(£ /$ mile) for the average vehicle each year. The percentage change in $P$ each year is multiplied by the elasticity of travel demand $\delta_{\text {Rebound }}$ and thereby modify future average vehicle mileage $M$ :

$$
M_{y+1}=M_{y} \times\left[1+\delta_{\text {Rebound }} \times \frac{P_{y}-P_{y+1}}{P_{y}}\right]
$$

\subsubsection{Modelling the efficiency of new vehicles}

The real-world fuel efficiency of vehicles from model years 2001-2018 is sourced from past work by the authors (Craglia and Cullen, 2019). These are linearly extrapolated backwards to 1994 in order to attain the fuel efficiency of all vehicles in use in the base year 2018. The average fuel efficiency of BEVs and PHEVs in 2018 on the WLTP cycle are sourced from (VCA, 2019) and increased by $10 \%$ to account for differences between WLTP and on-road driving.

The fuel efficiency of future new vehicles by model year, $\mathrm{FE}_{\mathrm{MY}, f}(\mathrm{MJ} / \mathrm{km})$ is estimated from equation 14, which multiplies the fuel efficiency of new vehicles in 2018, $\mathrm{FE}_{\mathrm{MY}=2018, f}$ by a factor representing incremental technical efficiency improvements (ITEI) in the future.

Between 2001 and 2018, ITEI reduced the fuel consumption of new vehicles, independent of vehicle size and power, by around $-1.3 \%$ year-on-year across petrol, diesel and hybrid vehicles (Craglia and Cullen, 2019). The future rate of ITEI is allowed to vary by a factor TI, representing the rate of Technical Improvements. When $\mathrm{TI}=1$ then the historical rate of improvements are assumed to continue into the future. $\mathrm{TI}=0.5$ assumes the historical rate of ITEI halves.

The term VA_FE $E_{\mathrm{MY}, f}(\mathrm{MJ} / \mathrm{km})$ is included to account for the change in new vehicle fuel efficiency, compared to base year 2018, due to changing vehicle attributes such as power and size. These could have an effect upon the fuel efficiency of vehicles and could offset technical improvements.

$$
\mathrm{FE}_{\mathrm{MY}, f}=(\mathrm{FE}_{\mathrm{MY}=2018, f} \times \overbrace{(1-0.013)^{\mathrm{TI} \times[\mathrm{MY}-2018]}}^{\text {ITEI }})+\mathrm{VA} \_\mathrm{FE}_{\mathrm{MY}, f}
$$

VA_FE $E_{\mathrm{MY}, f}(\mathrm{MJ} / \mathrm{km})$ is estimated using equation 15, where changes in power $(\mathrm{kw})$ and frontal area $\left(\mathrm{m}^{2}\right)$ of vehicles between model year 2018 and future model year MY, are multiplied by sensitivity coefficients $\beta_{f}$ of each powertrain type. The coefficients for ICE and HEVs are sourced from the data of Craglia and Cullen (2019), shown in table 1, and are assumed to remain constant over time in line with trends since 2001. The coefficients for electric vehicles are estimated by regression, based on data from the US EPA Fuel Economy database (EPA, 2020) (full regression results in SI).

$$
\mathrm{VA}_{-} \mathrm{FE}_{\mathrm{MY}, f}=\Delta \text { Power }_{\mathrm{MY}} \times \beta_{\text {Power }, f}+\Delta \text { Area }_{\mathrm{MY}} \times \beta_{\text {Area }, f}
$$

If vehicle attributes remain constant at 2018 levels (i.e. $\mathrm{VA}_{-} \mathrm{FE}_{\mathrm{MY}, f}=0$ ), then the energy efficiency of a vehicle of fuel type $f$ in a future model year MY would be adjusted solely by ITEI:

$$
\mathrm{FE}_{\mathrm{MY}, f}=\mathrm{FE}_{\mathrm{MY}=2018, f} \times(1-0.013)^{\mathrm{TI} \times[\mathrm{MY}-2018]}
$$




\begin{tabular}{llrr} 
Powertrain & $f$ & $\begin{array}{l}\beta_{\text {Power }} \\
(\mathrm{MJ} / \mathrm{km} \mathrm{kW})\end{array}$ & $\begin{array}{l}\beta_{\text {Area }} \\
\left(\mathrm{MJ} / \mathrm{km} \mathrm{m}^{2}\right)\end{array}$ \\
\hline Internal combustion engine & $\mathrm{ICE}$ & $8.642 \times 10^{-} 3$ & 0.653 \\
Hybrid electric vehicle & $\mathrm{HEV}$ & $6.637 \times 10^{-} 3$ & 0.632 \\
PHEV in ICE mode & PHEV $_{\mathrm{ICE}}$ & $5.375 \times 10^{-} 3$ & 0.571 \\
PHEV in EV mode & PHEV $_{\mathrm{EV}}$ & $2.181 \times 10^{-} 3$ & 0.293 \\
Battery electric vehicle & $\mathrm{BEV}$ & $0.155 \times 10^{-} 3$ & 0.221 \\
\hline
\end{tabular}

Table 1: Sensitivity coefficients between vehicle attributes (frontal area and power) and vehicle energy efficiency. Full regression results in SI table 1.

The emissions intensity of a vehicle $\eta_{y, \mathrm{MY}, f}\left(\mathrm{gCO}_{2} / \mathrm{km}\right)$ in year $y$, with model year MY and powertrain $f$ is determined from equation 16 . The fuel efficiency of each type of vehicle in each year is multiplied by the carbon intensity of the energy source used $\alpha_{y, f}\left(\mathrm{gCO}_{2} / \mathrm{MJ}\right)$. For battery electric vehicles and PHEVs driven in EV mode, $\alpha_{y, f}$ is the carbon intensity of grid electricity and is allowed to change over time. For vehicles with an internal combustion engine $\alpha_{y, f}$ is assumed constant at 2018 average levels of petrol and diesel, and scaled by the efficiency of petroleum refining assumed to be $90.4 \%$ from GREET (ANL, 2019).

$$
\eta_{y, \mathrm{MY}, f}=\mathrm{FE}_{\mathrm{MY}, f} \times \alpha_{y, f}
$$

The overall emissions intensity of plug-in hybrid vehicles (PHEV) is estimated using the emissions intensity during ICE and EV operation according to equation 17, where $U_{\text {PHEV }}$ is the percentage of total driving by PHEVs undertaken in all-electric mode, known as the utilisation factor.

$$
\eta_{y, \mathrm{MY}, \mathrm{PHEV}}=\eta_{y, \mathrm{MY}, \mathrm{PHEV}_{\mathrm{ICE}}} \times\left(1-U_{\mathrm{PHEV}}\right)+\eta_{y, \mathrm{MY}, \mathrm{PHEV}_{\mathrm{EV}}} \times U_{\mathrm{PHEV}}
$$

The annual well-to-wheel emissions (WTW) from the British fleet is calculated by multiplying the number of registered vehicles $V$ by the share of new sales $S$ of each powertrain, an age-dependent mileage $M_{y, \mathrm{MY}}$ and the vehicles' emissions intensity $\eta$. The mileage $M$ of vehicles drops by $\approx 330$ miles/year as the vehicle ages, as shown in past work by the authors Craglia and Cullen (2020). Base levels of emissions intensities for each powertrain are included in the SI.

$$
\mathrm{WTW} \mathrm{CO}_{2, y}=\sum_{\mathrm{MY}, f} V_{y, \mathrm{MY}} \times S_{\mathrm{MY}, f} \times M_{y, \mathrm{MY}} \times \eta_{y, \mathrm{MY}, f} \times 1.6
$$

\subsubsection{Modelling Embodied emissions}

Embodied emissions from vehicle manufacture are based on vehicle weight. The weight of future vehicles is estimated using equation 19, in a similar way to equation 14, by scaling the average weight in base year 2018 by a factor representing technical weight-saving improvements.

Between 2001 and 2018, the weight of new vehicles, independent of vehicle size and power, reduced by $0.4 \%$ year-on-year (regression results in SI table 4 ). This historical rate of weightsaving is allowed to vary in the future by a factor representing the rate of Technical Improvements, TI. This is the same factor used to scale incremental technical efficiency improvements in equation 14 .

$$
\text { Weight }_{\mathrm{MY}, f}=(\text { Weight }_{\mathrm{MY}=2018, f} \times \overbrace{(1-0.004)^{\mathrm{TI} \times[\mathrm{MY}-2018]}}^{\text {Light-weighting }})+\text { VA_Weight }_{\mathrm{MY}, f}
$$


The effect of future changes in vehicle attributes on vehicle weight are accounted for with the term VA_Weight ${ }_{M Y, f}$ calculated using equation 20. In general, larger and more powerful vehicles have higher mass. The effects of increasing frontal area and power on vehicle weight are presented in table 2. Note, the vehicle weight variable only affects embodied emissions. The impact of increasing vehicle size on WTW emissions is accounted for via vehicle frontal area and power coefficients (table 1) and the effect of light-weighting on fuel efficiency is accounted for in ITEI.

\begin{tabular}{llrr} 
VA_Weight $_{\mathrm{MY}, f}=\Delta$ Power $_{\mathrm{MY}} \times \phi_{\text {Power }, f}+\Delta$ Area $_{\mathrm{MY}} \times \phi_{\text {Area }, f}$ \\
Powertrain & $f$ & $\begin{array}{l}\phi_{\text {Power }} \\
(\mathrm{kg} / \mathrm{kW})\end{array}$ & $\begin{array}{r}\phi_{\text {Area }} \\
\left(\mathrm{kg} / \mathrm{m}^{2}\right)\end{array}$ \\
\hline Internal combustion engine & $\mathrm{ICE}$ & 2.647 & 846.74 \\
Hybrid electric vehicle & $\mathrm{HEV}$ & 3.426 & 859.4 \\
Plug-in electric vehicle & $\mathrm{PHEV}$ & 1.887 & 581.4 \\
Battery electric vehicle & $\mathrm{BEV}$ & 1.169 & 670.2 \\
\hline
\end{tabular}

Table 2: Sensitivity coefficients between vehicle attributes (frontal area and power) and vehicle weight. Full regression results in SI table 2.

One of the most carbon intensive components of electric vehicles is the battery. The weight of the battery is calculated using an energy density of $7 \mathrm{~kg} / \mathrm{kWh}$ (IEA, 2019). Future battery weight is estimated according to equation 21 in a similar way to equations 14 and 19 . Future battery light-weighting is conservatively assumed to proceed in a similar manner to that of the entire vehicle.

$$
\text { BatWeight }_{\mathrm{MY}, f}=(\text { BatWeight }_{\mathrm{MY}=2018, f} \times \overbrace{(1-0.004)^{\mathrm{TI} \times[\mathrm{MY}-2018]}}^{\text {Light-weighting }})+\text { VA_BatWeight }{ }_{\mathrm{MY}, f}
$$

The battery capacity requirements of an electric vehicle are broadly determined by its size and power, increasing the size and power of future vehicles will likely require additional battery capacity with additional weight (VA_BatWeight ${ }_{M Y, f}$ ), this is accounted for in equation 22 .

$$
\text { VA_BatWeight }_{\mathrm{MY}, f}=\Delta \text { Power }_{\mathrm{MY}} \times \lambda_{\text {Power }, f}+\Delta \text { Area }_{\mathrm{MY}} \times \lambda_{\text {Area }, f}
$$

\begin{tabular}{llrr} 
Powertrain & $f$ & $\begin{array}{l}\lambda_{\text {Power }} \\
(\mathrm{kg} / \mathrm{kW})\end{array}$ & $\begin{array}{l}\lambda_{\text {Area }} \\
\left(\mathrm{kg} / \mathrm{m}^{2}\right)\end{array}$ \\
\hline Battery electric vehicle & BEV & 1.079 & 98.89 \\
Plug-in electric vehicle & PHEV & 0.039 & 7.09 \\
\hline
\end{tabular}

Table 3: Sensitivity coefficients between vehicle attributes (frontal area and power) and vehicle battery weight. Full regression results in SI table 3.

Embodied emissions associated with the manufacture of vehicles (eqn. 23) are assumed to be $3.6 \mathrm{kgCO}_{2} \mathrm{e}$ per $\mathrm{kg}$ of vehicle mass, similar to recent work (Hoekstra, 2019), and are conservatively assumed to remain constant over time.

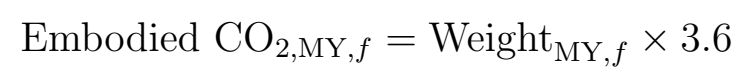

For electric vehicles, the embodied emissions associated with the battery are calculated separately from rest of the vehicle, as $65 \mathrm{kgCO}_{2} \mathrm{e}$ per $\mathrm{kWh}$ of battery capacity, from the latest 
literature (Hoekstra, 2019). Embodied emissions for electric vehicles (both PHEV and BEV) are then calculated according to equation 24.

$$
\text { Embodied } \mathrm{CO}_{2, \mathrm{MY}, f}=\text { BatWeight }_{\mathrm{MY}, f} \times \frac{65}{7}+\left(\text { Weight }_{\mathrm{MY}, f}-\text { BatWeight }_{\mathrm{MY}, f}\right) \times 3.6
$$

The total annual embodied emissions associated with the manufacture of new vehicles is calculated according to equation 25.

$$
\text { Embodied } \mathrm{CO}_{2, y}=\sum_{f} \text { New } \mathrm{Cars}_{y} \times S_{\mathrm{MY}, f} \times \text { Embodied } \mathrm{CO}_{2, \mathrm{MY}, f}
$$

The total life-cycle emissions from passenger vehicles is then determined by the addition of annual WTW emissions and embodied emissions (equation 26). The future variance of each input parameter is detailed in the next section. The stock model is calibrated to Department for Transport statistics (DfT, 2019b). Input variables are iteratively fed into the stock model using Monte Carlo methods to produce a series of outputs. Sobol indices are calculated using the SobolEff function from the 'sensitivity' package in the $\mathrm{R}$ coding environment. The stock model is run $\mathrm{n}=6000$ times until convergence is achieved.

$$
\text { Life-cycle } \mathrm{CO}_{2, y}=\mathrm{WTW} \mathrm{CO}_{2, y}+\text { Embodied } \mathrm{CO}_{2, y}
$$

\subsection{Estimating input variance}

A broad range of possible futures are considered in this analysis. These are not all possible futures. Instead, an effort is made to consider a wide range of futures that would not require particularly significant changes in lifestyles. In theory, we could immediately stop buying internal combustion engined vehicles, or we all could choose to take public transport, or stop driving altogether. These actions would have significant effects on carbon emissions, however the probability of these actions occurring remains low and politically challenging.

The range of futures investigated in this paper are constrained by an upper and lower bound for each input variable into the model. Government policy announcements are used where possible to inform the ranges of input variables, though this is limited for variables that are more behavioural in nature (e.g. trends in vehicle size). To minimise making arbitrary judgements about the most likely value of a specific parameter, or the shape of an input variables' distribution, a uniform distribution is used for each model input parameter between its upper and lower bound. This allows for a relatively unbiased assessment of the impact of each variable on the model results. The range of the input variables are summarised in table ?? and are detailed further in the following sections.

\subsubsection{Technical improvements, TI}

The upper bound for the rate of technical improvements (TI) in new vehicles is assumed to be a $50 \%$ increase from the historical rate. This is not outside the physical realms of possibility given the large potential for improvements in both conventional internal combustion engined vehicles (Paoli and Cullen, 2019) and in battery technologies in electric vehicles. In an ambitious scenario with high incremental technical efficiency improvements and coupled with reductions in the size and power of vehicles, the average vehicle on the road in 2050 could have a fuel consumption similar to the Volkswagen XL1 concept car (using just 1 L/100km) (Top Gear. 2017). This could be stimulated by increasingly stringent government policy or via increases in R\&D. In a more pessimistic future, the rate of ITEI could decrease by $50 \%$ (lower bound), for example if potential improvements become difficult to unlock in practice or if manufacturers have little incentive to apply technologies to vehicles. 


\subsubsection{Vehicle attributes}

The size and power of vehicles have increased over time with each new vehicle generation becoming larger and more powerful than the generation it replaces. Between 2001 and 2018, the average new vehicle had $1.7 \mathrm{~kW}$ more power than the previous year and $138 \mathrm{~cm}^{2}$ more frontal area. Two different futures are envisaged. Firstly, the rate of increase in size and power could double, as manufacturers aim to satisfy consumer demand for increasingly large and powerful vehicles resulting in the average vehicle in 2050 being similar to that of the USA and Canada today. Conversely, the historical rate could be reversed (i.e. reductions of $1.7 \mathrm{~kW}$ and $138 \mathrm{~cm}^{2}$ per year), due to a shift in the way manufacturers market vehicles to the general public.

\subsubsection{Electricity grid emissions intensity}

The uncertainty associated with the carbon intensity of grid electricity is estimated using two scenarios produced by National Grid in their annual Future Energy Scenarios publication (National Grid ESO, 2019). The range of futures (shown in fig. 2) is defined by the optimistic 'Two Degrees' scenario, 2DS (consistent with reaching a 2 degrees warming target, largely by rolling out low carbon electricity generation, a high share of electric vehicles and electric and hydrogen home heating) and the more pessimistic 'Consumer Evolution' scenario, CES (in which 'the pace of the low-carbon transition continues at a similar rate to today but then slows towards 2050'(National Grid ESO, 2019)). These scenarios are used as the upper (CES) and lower bounds (2DS) for the range of grid emission intensities (shown highlighted in yellow).

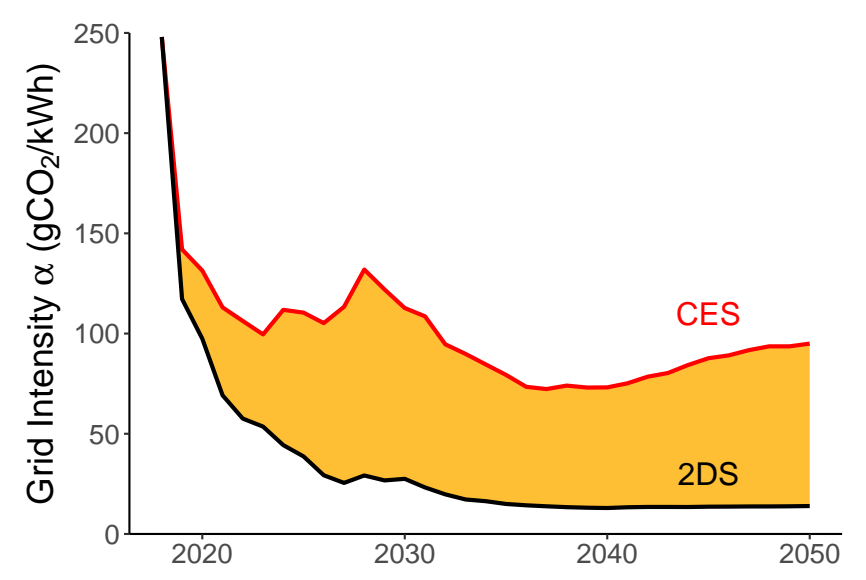

Figure 2: National Grid two degrees (black) and Consumer Evolution (red) scenarios and range used in this analysis (yellow).

\subsubsection{Vehicle powertrain technology uptake}

The UK government is currently consulting on whether to set a new target for $100 \%$ of new car sales in 2035 to be 'Ultra Low Emission Vehicles' (ULEVs) (Campbell, 2020). ULEVs include battery electric (BEV), plug-in hybrid vehicles (PHEV) and hydrogen fuelled vehicles. Such a target will effectively ban the sale of conventional internal combustion engined vehicles (including hybrid electric vehicles) from 2035 onwards. This relatively ambitious goal is used as the upper bound in the range of possible futures. The lower bound for the uptake of ULEV vehicles assumes this target is achieved 15 years later in 2050 .

Hydrogen fuelled passenger cars are not considered in this analysis; the latest report by the UK Committee on Climate Change argues 'battery electric vehicles are now well placed to deliver the bulk of decarbonisation for cars and vans' (CCC, 2018) and the focus of current 
government policy documents is on electric vehicles (DfT, 2020). This is further reinforced by recent manufacturer announcements ending $R \& D$ for fuel cell vehicles in favour of electric vehicles (Berman, 2020).

An additional reason for not including hydrogen vehicles is that their market uptake is highly coupled with infrastructure deployment and the carbon intensity of hydrogen. This means the two variables (carbon intensity of hydrogen and uptake of hydrogen vehicles) are highly dependent in ways that are difficult to model. Electricity in comparison is less affected by this relationship given electric generation capacity is widely available today and used across a broad range of sectors.

The ULEVs considered in this analysis are therefore either BEV or PHEV. However, it is not clear which will attain a higher market share in future. The share of BEV within sales of ULEVs in 2050 is allowed to vary between $20 \%$ to $80 \%$ to examine a range of possible futures. Similarly, the share of hybrid electric vehicles within total ICE vehicle sales is also allowed to vary between $20 \%$ to $80 \%$ in 2050 . Sales trends are assumed to be linear between the base year 2018 and 2050. Finally, the utilisation factor of PHEVs, $U_{\mathrm{PHEV}}$, is allowed to vary between $50 \%$ and $90 \%$ (for all years).

\subsubsection{The Rebound effect}

Efficiency improvements in vehicles tend to reduce running costs, which could stimulate travel demand. The upper bound of the rebound effect is assumed to be: $\delta_{\text {Rebound }}=0.3$. This is at the high end of the literature (Goodwin et al., 2004, Dimitropoulos et al., 2016) and is calculated using many data points from older years. However, there is some evidence that the rebound effect may have decreased over time with growing vehicle ownership and saturating travel demand in developed economies (Hughes et al., 2008). The lower bound estimate used here is $\delta_{\text {Rebound }}=0.046$ from Craglia and Cullen (2020), based on a short-run calculation of the rebound effect for Great Britain.

\subsubsection{Modal shift}

In 2018, $83 \%$ of total domestic passenger miles travelled (PMT) in the Great Britain were by car (DfT, 2019b). The UK National Travel Survey (NTS, 2019) is used to inform possible futures regarding travel modes. The survey responses for years 2015 to 2017 and covering over 600,000 individual trips, are used to produce figure 3, which shows the cumulative percentage share of trips (left) and passenger miles travelled (right) by trip distance. This shows that $50 \%$ of trips by car are below 4 miles; these are prime trips to shift to other modes including cycling, walking and public transport. However, they account for just $13 \%$ of PMT travelled by car and it may not be possible to shift all of these short distance trips to low carbon modes of transport.

Similarly, $8.25 \%$ of trips by car are above 20 miles but these account for $50.5 \%$ of PMT by car. If just a small share of these trips could be shifted to alternative modes, the impact on PMT by car would be significant. However, there are fewer modes that can satisfy this demand for longer distance trips, as cycling, underground and walking are not feasible. Just $2.1 \%$ of trips by bus are over 20 miles in distance, suggesting significant barriers to growth. On the other hand, longer distance trips are common for rail, as $41 \%$ of rail trips are above 20 miles. Increasing rail travel by $100 \%$, a challenging prospect by 2050 , would reduce the mode share of car travel by approximately $6 \%$. If an additional $40 \%$ of car trips below 4 miles could be shifted to cycling, walking or public transport a further $4 \%$ of car PMT could be reduced. The lower bound (high ambition) used for mode shift in this paper is therefore $10 \%$ lower than 2018 levels (73\% of total PMT). This is similar to a high mode shift scenario used by the UK Committee on Climate Change (CCC, 2015). An upper bound of $90 \%$ mode share is used to account for 
the potential negative effects of autonomous vehicles reducing public transport demand in the future (Wadud et al., 2016).
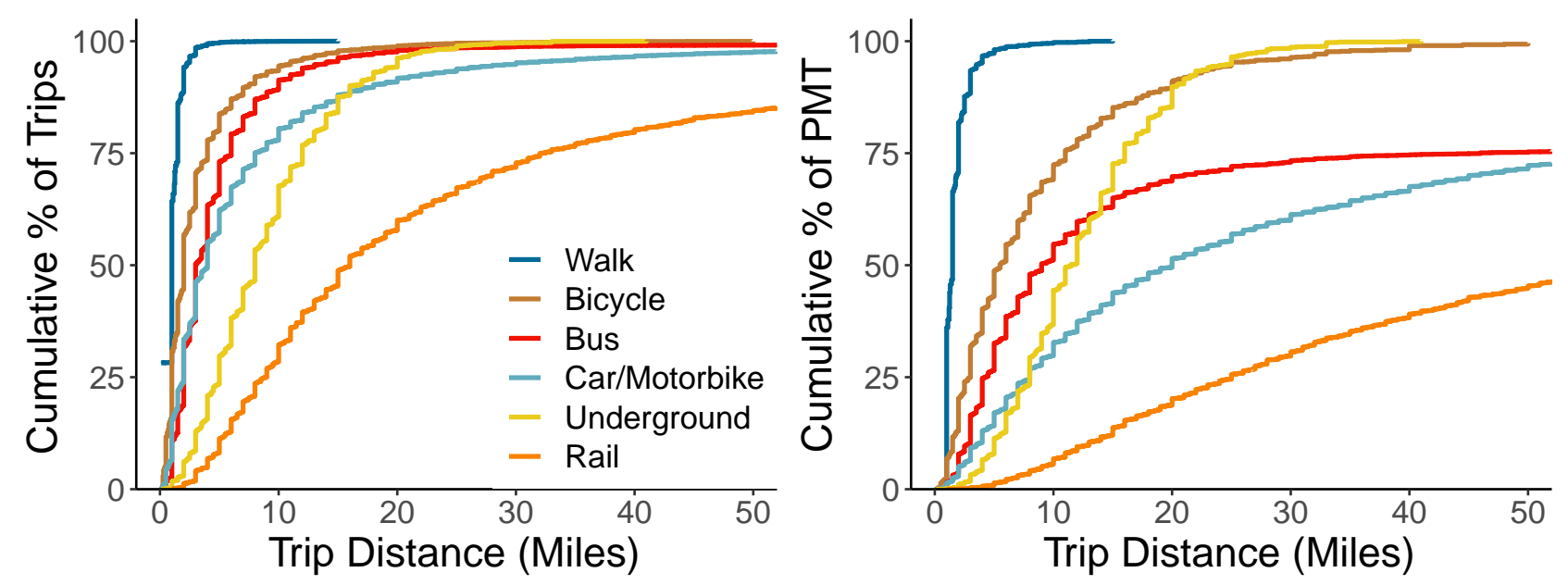

Figure 3: Cumulative $\%$ of trips by trips distance (left) and cumulative $\%$ of passenger miles travelled (PMT) by trip distance.

Together, these ranges of input variables shown in table ??, define a likely solution space for future transport $\mathrm{CO}_{2}$ emissions in Great Britain. Sobol sensitivity indices are used to determine how much of the variance/uncertainty of future emissions can be attributed to each input variable. Variables are defined as 'important' if they cause a large amount of variance in future emissions (and therefore have a relatively large Sobol index). Important variables require particular attention in policy and regulation to ensure their future trajectory is in line with their lower bound, thus reducing emissions. Variables that have a negligible impact upon future variance in transport $\mathrm{CO}_{2}$ emissions are of lower priority. Tackling climate change requires reducing the total cumulative quantities of greenhouse gases in the atmosphere; Sobol indices are therefore calculated on total cumulative emissions for the 2019-2050 period.

\subsection{Limitations}

The use of Sobol indices provides a transparent approach to rank interventions to reduce emissions accounting for both interactions between variables and their respective uncertainties. However, Sobol indices cannot address uncertainty in the structure of a model. For example, in this study the impact of mode shift does not account for the emissions of the alternative mode (bus or rail).

\section{Results}

This section begins by showing the possible variance in each of the input variables and how their uncertainty propagates through the stock model to result in a range of possible futures of transport demand, energy use and $\mathrm{CO}_{2}$ emissions. The variance of these model outputs is then examined using Sobol indices to highlight the relative importance of input variables. 


\subsection{Model inputs and outputs}
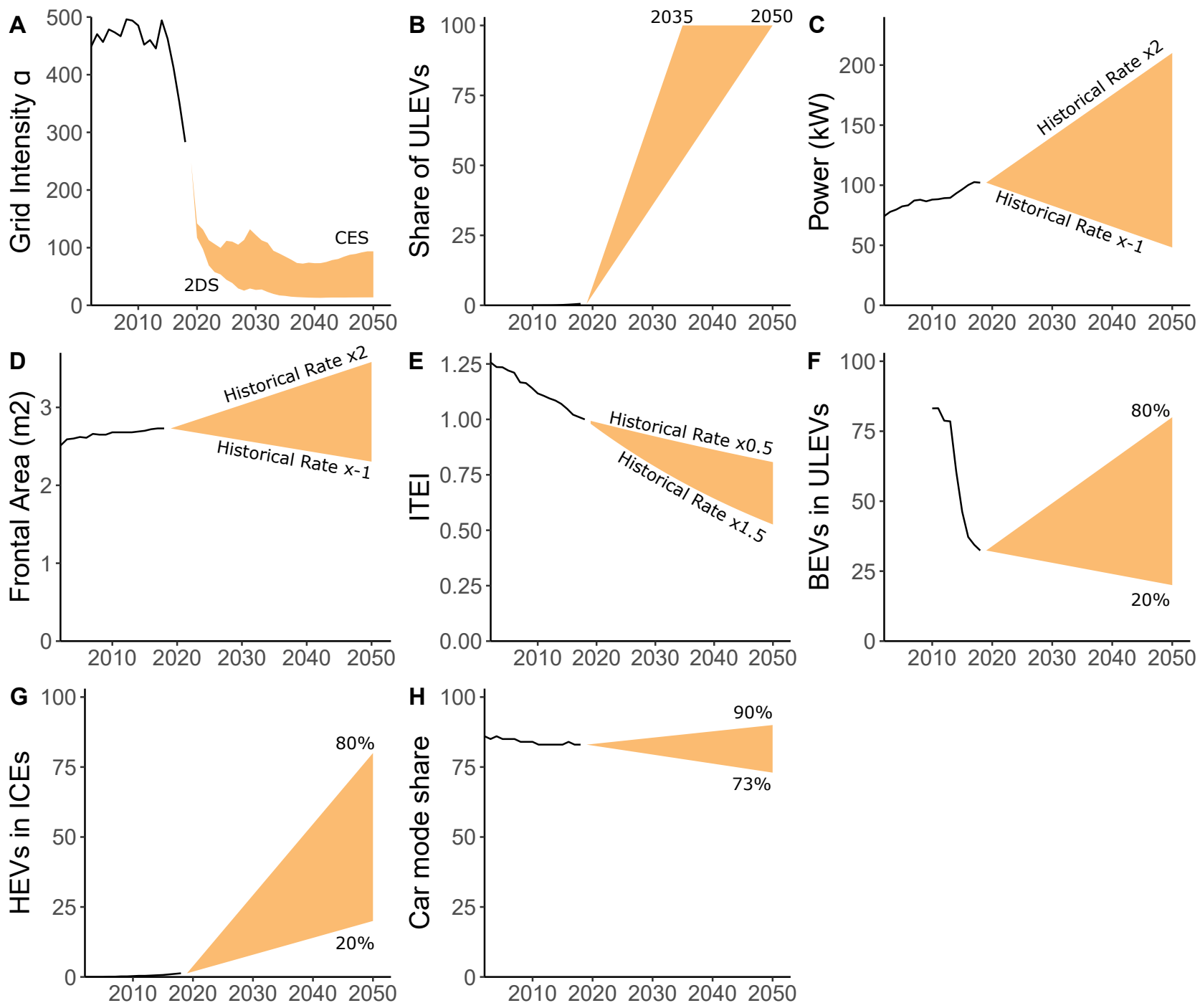

Figure 4: Ranges for each input parameter (yellow) with historical values shown as black lines. From top left to bottom right: (A) Carbon intensity of grid electricity $\left(\mathrm{gCO}_{2} / \mathrm{kWh}\right),(\mathbf{B})$ share of ULEVs in new car sales, $(\mathbf{C})$ average power of new vehicles $(\mathrm{kW}),(\mathbf{D})$ average frontal area $\left(\mathrm{m}^{2}\right),(\mathbf{E})$ incremental technical efficiency improvements (ITEI), (F) share of battery electric vehicles (BEVs) in ULEV sales, $(\mathbf{G})$ share of hybrid electric vehicles in ICE sales, $(\mathbf{H})$ share of total national passenger miles travelled delivered by car.

Figure 4 presents the future uncertainty ranges for the model input variables $(\mathrm{A}-\mathrm{H}$, shown in yellow) and historical values from the year 2002 (black lines). The input variables are fed into the stock model producing output variables with a range of uncertainty, shown in figure 5 (I-K, shown in blue). The energy use of vehicles could drop significantly due to efficiency improvements (fig. 5 I) from vehicle light-weighting, technical improvements and reduced size and power. Figures $5 \mathrm{~J}-\mathrm{K}$ show the range of WTW and life-cycle emissions from the British vehicle fleet each year. Life-cycle emissions are larger as they include embodied emissions from vehicle manufacture. Annual emissions are likely to drop in all scenarios by 2050 due to a certain degree of incremental technical efficiency improvements and the eventual uptake of electric vehicles. However, the range of futures varies widely; ambitious futures lead to WTW emissions reaching close to zero by 2050, whilst in the upper bound they drop by just $30 \%$. 

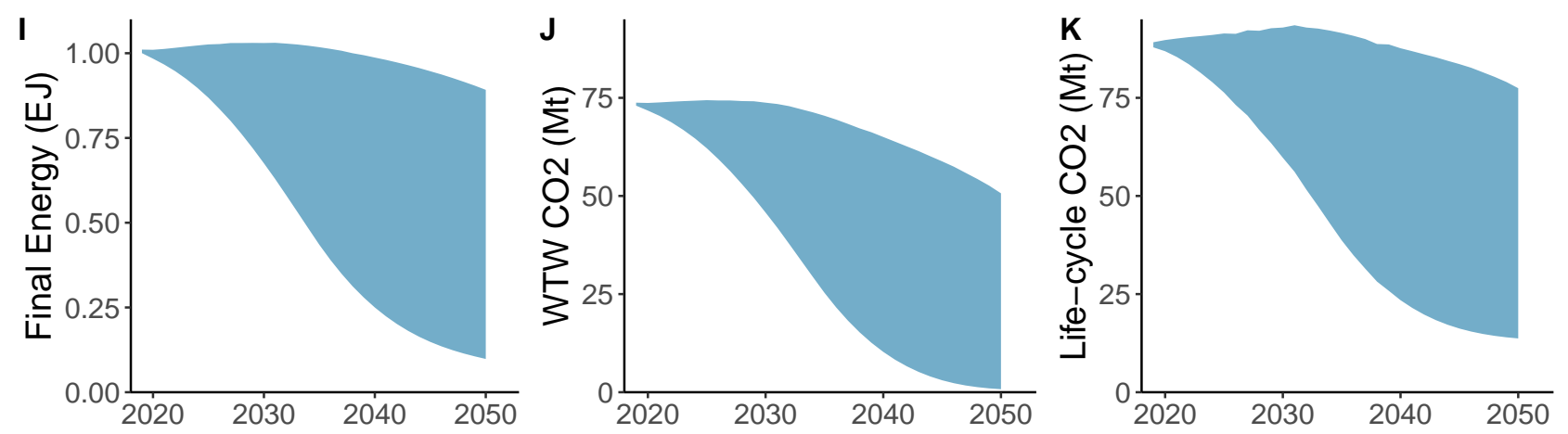

Figure 5: Ranges for output variables (blue), from left to right: (I) total annual final energy use (EJ), $(\mathbf{J})$ total annual WTW $\mathrm{CO}_{2}$ emissions and $(\mathbf{K})$ total annual life-cycle $\mathrm{CO}_{2}$ emissions (including manufacturing emissions of new cars).

\subsection{Important factors for $\mathrm{CO}_{2}$ emissions}

Figure 6 (left) presents the range of total cumulative $\mathrm{CO}_{2}$ emissions between years 2019 and 2050, calculated on both a WTW and a life-cycle basis. The range of future emissions results directly from the uncertainty/variance in the input variables. However, figure 6 (left) gives no indication of which variables exert more (or less) influence over the variance in emissions, this requires sensitivity analysis.

The Sobol indices are used to determine which are the most important variables with the greatest impact on cumulative emissions, and are presented in figure 6 (right) and table ?? for both Well-to-Wheel (WTW) and life-cycle cumulative emissions of the British fleet for the period 2019-2050. A larger Sobol index, indicates that a larger share of the variance is explained by a particular variable, meaning this variable has a greater impact on the future.

The variable with the largest impact on cumulative Well-to-Wheel emissions is the year that internal combustion engine vehicles are banned (ICE End Year) and replaced with ULEVs in new car sales. This determines the share of ULEVs in the fleet and explains $66 \%$ of the variance in cumulative WTW emissions. This is followed by the rate of change of vehicle attributes (Rate of VA) which explains 21\%. The majority of travel in Great Britain (both currently and in the likely future) is by private passenger car, meaning efforts to improve the emissions intensity of vehicles, either by electrification or by reducing their size and power, have a significant impact on future cumulative emissions.

The rate of Technical Improvements (TI) explains just 3\% of future variance, meaning their role is relatively minor in reducing cumulative emissions, since improvements are relatively small and incremental. Similarly, the share of travel by car, also has a relatively minor impact on future $\mathrm{CO}_{2}$ emissions as displacing the passenger car, with current levels of travel demand, is challenging. The rebound effect has a negligible impact on cumulative emissions, indicating induced demand is unlikely to greatly offset energy efficiency improvements. 

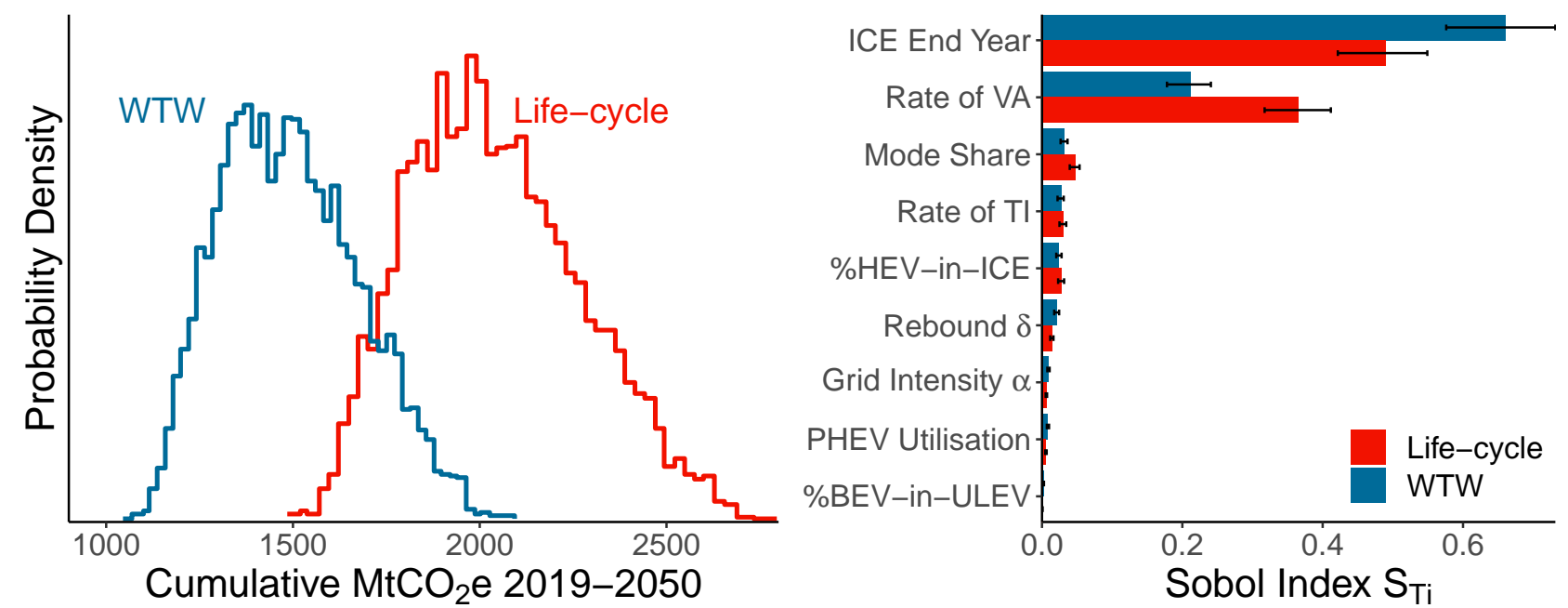

Figure 6: Left= Probability density of cumulative Well-to-Wheel and life-cycle $\mathrm{CO}_{2}$ emissions (left) for the full British vehicle stock, years 2019-2050. Right= Sobol indices $S_{T i}$ for each input variable and standard errors (SE) on cumulative $\mathrm{CO}_{2}$ emissions 2019-2050.

Shifting to ULEV vehicles has the largest impact on cumulative emissions because electric vehicles represent a step change in emissions intensity compared with internal combustion engine vehicles. This is true even under the more conservative grid carbon intensity futures (meaning grid carbon intensity is not a variable of high importance). More incremental improvements such as shifting to HEVs, have a negligible impact on future cumulative emissions. Similarly, the share of BEVs in total ULEV sales makes little difference as plug-in hybrid vehicles still represent a step change in emissions intensity; this also means the Utilisation factor has a negligible impact on emissions (provided it remains between 50-90\%).

Input variables have a similar importance when using life-cycle emissions, rather than wellto-wheel. However the importance of the last year ICE vehicles are sold drops from $66.1 \%$ down to $49 \%$. There are two main reasons for this change. Including the emissions from vehicle manufacture reduces the difference in emissions intensity of driving an electric vehicle compared with an ICE vehicle, thereby partly reducing the emission benefits of the uptake electric vehicles. Additionally, including the emissions from vehicle manufacture adds importance (from $21.2 \%$ to $36.5 \%$ ) to future trends in vehicle size and power, which can effect embodied emissions through vehicle weight.

Manufacturing emissions were conservatively assumed to remain constant in this study. As industries decarbonise over time the carbon intensity of vehicle manufacture will likely decrease. If embodied emissions were to reduce for all vehicle powertrains equally, this would likely shift the life-cycle Sobol indices towards the magnitudes of the WTW indices (as these don't include emissions from manufacture).

\subsection{Important factors for Final energy use}

The previous section used Sobol indices to highlight the main factors that affect $\mathrm{CO}_{2}$ emissions. However, Sobol indices can also be used to explain the factors of different model outputs. Figure 7 (left) shows the variance of cumulative final energy use (electricity and petroleum fuel) of vehicles between 2019-2050. Figure 7 (right) then presents Sobol indices highlighting the input variables that explain the highest share of variance in cumulative energy use.

Vehicle attributes have the highest Sobol index when considering final energy use, as they explain $41 \%$ of future variance. The importance of ULEV share on energy use (via ICE end year) is lower than for $\mathrm{CO}_{2}$ emissions at $39.6 \%$. Electric vehicles have a lower energy intensity 
than internal combustion engine vehicles (on a final energy basis). However, their emissions intensity is significantly lower than ICE vehicles, meaning the importance of accelerating the shift to EVs is more apparent when considering $\mathrm{CO}_{2}$ emissions than when solely considering energy use. The importance of shifting to electric vehicles as a measure to reduce energy demand would be further reduced when considering primary energy demand rather than final energy, as the energy conversion efficiencies of power generation are lower than those of petroleum refining (ANL, 2019). Sobol indices on primary energy demand, though not considered here (as they would be dependent upon the types of fuels used in power generation), would likely further increase the relative importance of vehicle size and power, making it the factor with the highest impact at reducing future energy demand. This would be over three times more important than pursuing incremental technical efficiency improvements. Variables primarily associated with the $\mathrm{CO}_{2}$ emissions intensity of driving, such as the grid carbon intensity $\alpha$, have no impact on future energy use.
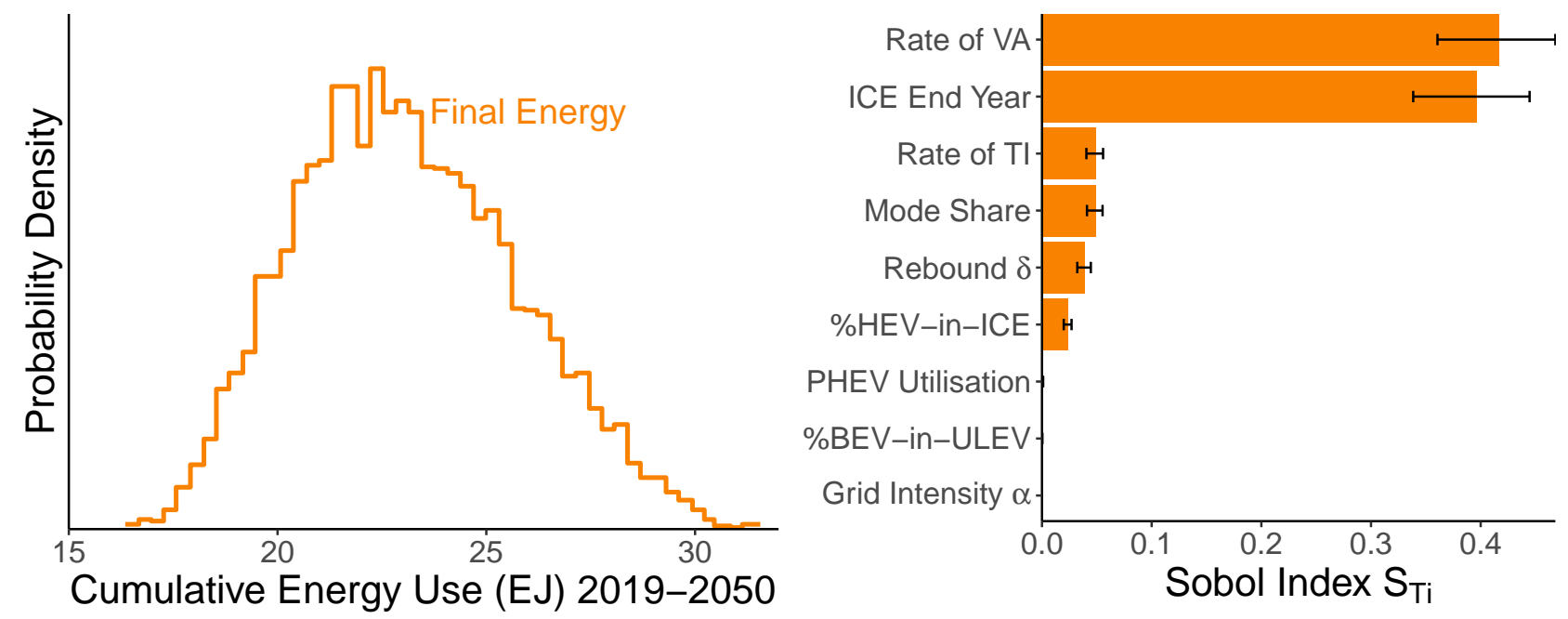

Figure 7: Left= Probability density of cumulative final energy use (right) for the full British vehicle stock, years 2019-2050. Sobol indices $S_{T i}$ for each input variable and standard errors (SE) on cumulative final energy use 2019-2050.

\subsection{Important factors for Travel demand}

Figure 8 shows the future solution space explored for vehicle kilometres by car. The main factors that explain travel demand in the model are the modal share between car travel and alternative modes, the magnitude of the rebound effect and the travel costs of vehicles, which are dictated by their fuel efficiency and fuel type (petroleum or electricity). If the magnitude of $\delta_{\text {Rebound }}$ is large and coupled with high energy efficiency improvements and a high passenger car modal share, then travel demand more than doubles by 2050 (shown as (1) in fig. 8). This is likely an extreme scenario as there are likely to be saturation effects in consumers' willingness to travel. It also assumes travel costs of electric vehicles remain relatively similar to today and no additional government duties (e.g. electricity taxes or road taxes) are introduced.

Conversely, if $\delta_{\text {Rebound }}$ is small (0.046) and coupled with low energy efficiency improvements and a low passenger car modal share, then travel demand is limited (shown as (2) in fig. 8). In (2), a portion of the reduced travel demand from modal shift to alternative modes is offset by population growth (see (3) in fig. 8) and induced demand from the rebound effect.

The rebound effect was found to be relatively unimportant on future $\mathrm{CO}_{2}$ emissions and energy use. However, it is of high importance to future trends in vehicle mileage as shown by the Sobol indices in figure 9 (right). Rebound is unimportant for $\mathrm{CO}_{2}$ and energy use because large 
increases in travel demand are only stimulated in the presence of large efficiency improvements, which more than offset the impact of increased demand. Interestingly, a common motivation for literature investigating the rebound effect is to better predict future energy use and the effects of energy efficiency policy. However, rebound is of much greater importance to travel demand and associated factors such as congestion.

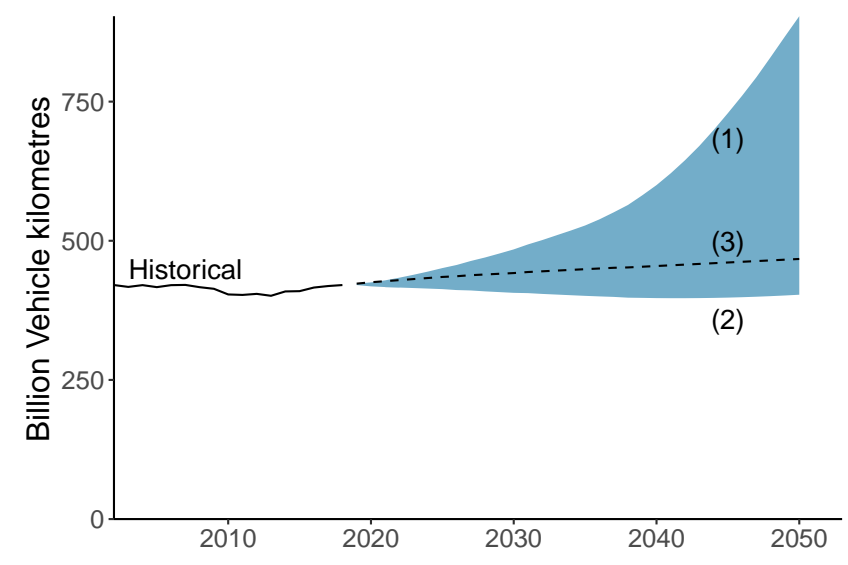

Figure 8: Historical (DfT, 2019b) and future projections of vehicle kilometres (vkm) under extreme scenarios: (1) Large rebound effect coupled with high efficiency improvements and mode shift towards passenger cars, (2) Small rebound effect coupled with low efficiency improvements and mode shift away from passenger cars. (3) shows how vkm would change from population growth alone with no effects of rebound or mode shift.

The second most important variable explaining future variance in travel demand is the mode share, followed by factors which affect the energy efficiency of vehicles (which stimulate rebound). Factors that primarily affect the emissions intensity of travel, such as the carbon intensity of the grid, are of little importance to travel demand.
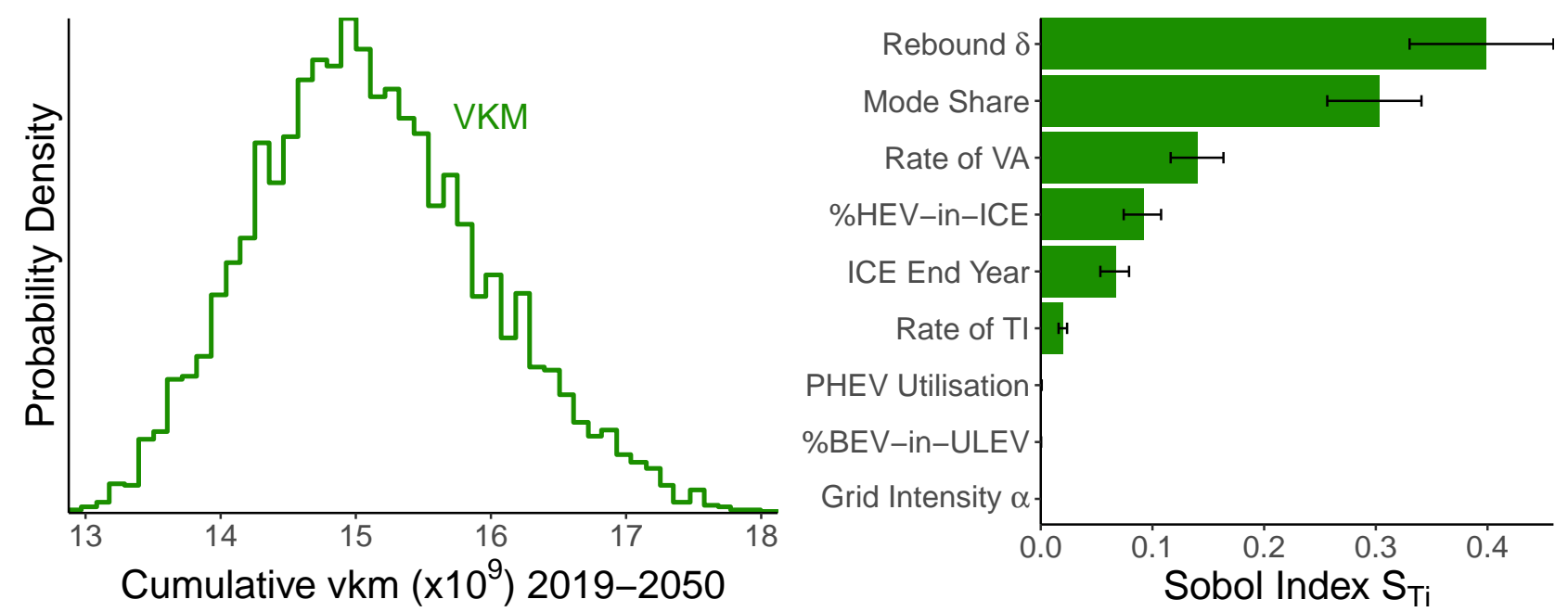

Figure 9: Left= Probability density of cumulative vehicle kilometres (vkm) for the full British vehicle stock, years 2019-2050. Right $=$ Sobol indices $S_{T i}$ for each input variable and standard errors (SE) on cumulative vehicle kilometres 2019-2050.

To summarise, Sobol indices are a versatile tool for highlighting the relative importance of variables and can be readily applied to a range of output variables of interest such as $\mathrm{CO}_{2}$ emissions, energy use and travel demand. Figure 10 presents the Sobol indices for each different 
output variable and highlights that the importance of input variables on future passenger car use can differ based on the output variable of interest. Some variables are consistently of low importance to future travel in Great Britain, these include incremental technical efficiency improvements, the utilisation factor of PHEVs, the grid carbon intensity and the share of BEVs in ULEV sales. These can be set to any value within their range without greatly affecting future $\mathrm{CO}_{2}$ emissions, energy use or travel demand and can therefore be safely excluded from the stochastic analysis.

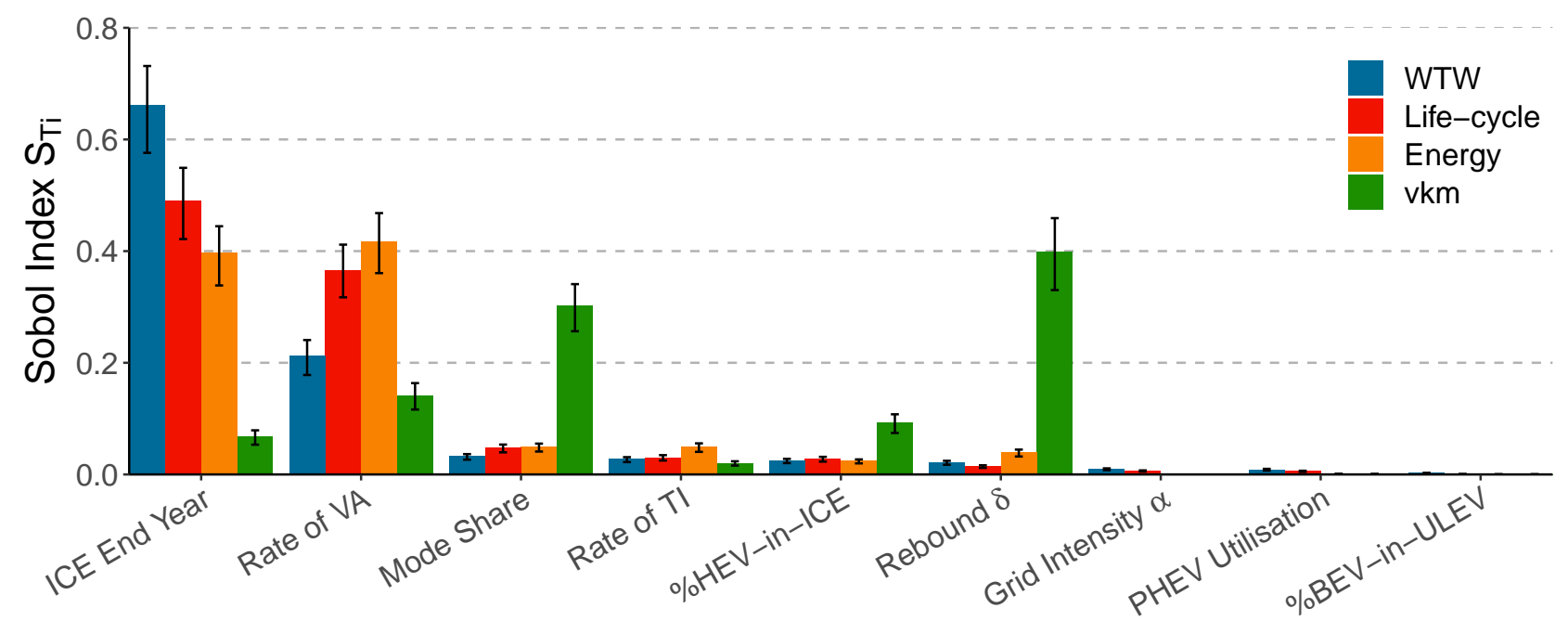

Figure 10: Sobol indices $S_{T i}$ for each input variable on cumulative WTW and life-cycle $\mathrm{CO}_{2}$ emissions, final energy use and vehicle kilometres 2019-2050.

\subsection{The effect of input variance}

Knowledge of the precise values to choose for input variables will always be imperfect. The aim of this analysis is to move the assessment of important variables from choosing single deterministic values, to exploring a wide solution space. The choice of upper and lower bounds is of course subjective and has an impact upon the results. For example, halving the variance of the ICE end year variable by modifying its upper bound to 2042 (from 2050), has the impact of reducing its life-cycle emissions Sobol index to 0.23, the vehicle attributes parameter increases to 0.51 , but all other parameters continue to explain less than $10 \%$ of the variance and thus remain relatively unimportant. If instead the variance in the rate of change of vehicle attributes (size and power) is halved (ranging between $-50 \%$ and $100 \%$ ), the life-cycle emissions Sobol index increases to 0.61 , the vehicle attributes parameter decreases to 0.14 , and all other parameters again continue to explain less than $10 \%$ of the variance. These two examples show that the relative importance of variables remain broadly similar. Sobol indices can therefore provide a simple and transparent way to assess the importance of different variables on a future solution space. This can help researchers modelling future demand to eliminate variables of low importance and prioritise critical variables to refine with further analysis or expert elicitation.

\subsection{Changing travel demand}

The previous section assessed plausible upper and lower bounds for different input variables without requiring particularly significant changes in lifestyles. This assumed that the underlying travel demand, the number of desired trips at different distances, remains constant and only the vehicles used to satisfy travel demand are changed (either via modal shift or technical changes to cars). Per capita vehicle kilometres by car were therefore only dependent on endogenous 
changes in rebound and mode shift. In this section, the effect of an exogenous change in per capita travel demand is investigated.

Figure 11 presents the future solution space investigated for travel demand. The upper bound (1) is similar to travel demand projections produced by the Department for Transport DfT (2018) under scenarios of high GDP growth and low fuel prices, which stimulate future travel demand following historical macroeconomic relationships. According to the ONS (2020), $45 \%$ of the British workforce was able to work from home in April and May 2020 during the COVID-19 pandemic. The lower bound (2) assumes future travel demand drops permanently by $20 \%$ from 2018 levels as a large share of the population $(\approx 20 \%)$ works from home and uses video conferencing software to minimise trips.

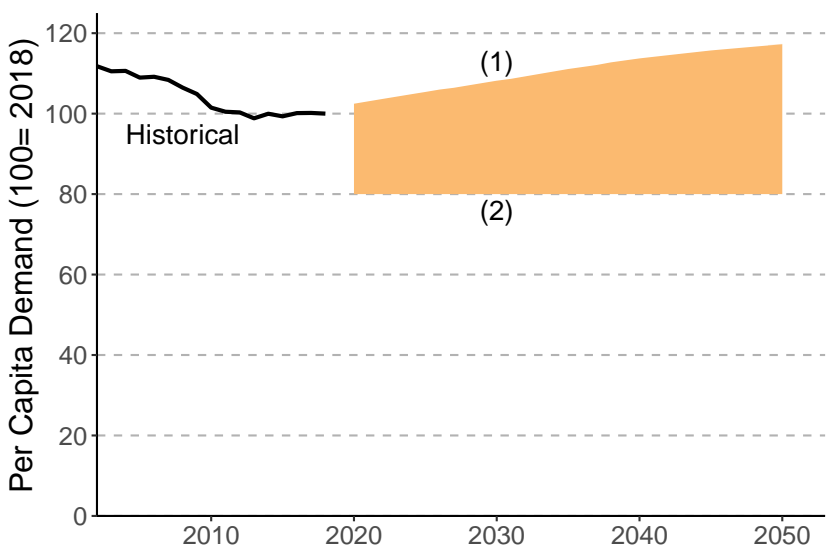

Figure 11: Historical and future projections of travel demand (indexed to 2018 levels) under extreme scenarios: (1) High GDP growth, low fuel prices and otherwise business-as-usual stimulate higher demand, (2) per capita travel demand drops by $20 \%$.

The future range of per capita travel demand is introduced as an additional exogenous stochastic variable to the analysis used in the previous section to account for macro-economic conditions affecting travel. The annual vehicle kilometres by the British fleet output by the model therefore has variance dictated both by rebound effects, modal shift and the macroeconomic conditions affecting travel demand. Variables with low Sobol indices in table ?? are set to their average values and therefore excluded from further analysis.

The effect of adding in uncertainty of future travel demand is presented in figure 12 for WTW emissions (left) and vehicle kilometres (right). A large drop in travel demand has the effect of shifting the likely solution space of future $\mathrm{CO}_{2}$ emissions and vehicle kilometres to lower values. However, this effect is more pronounced for vkm than it is for WTW emissions showing that changes in per capita demand have a larger effect on total vkm than on $\mathrm{CO}_{2}$ emissions. This is because futures with low cumulative $\mathrm{CO}_{2}$ emissions already have efficient, low emission vehicles meaning further reductions in vkm only have slight impacts on cumulative emissions. 

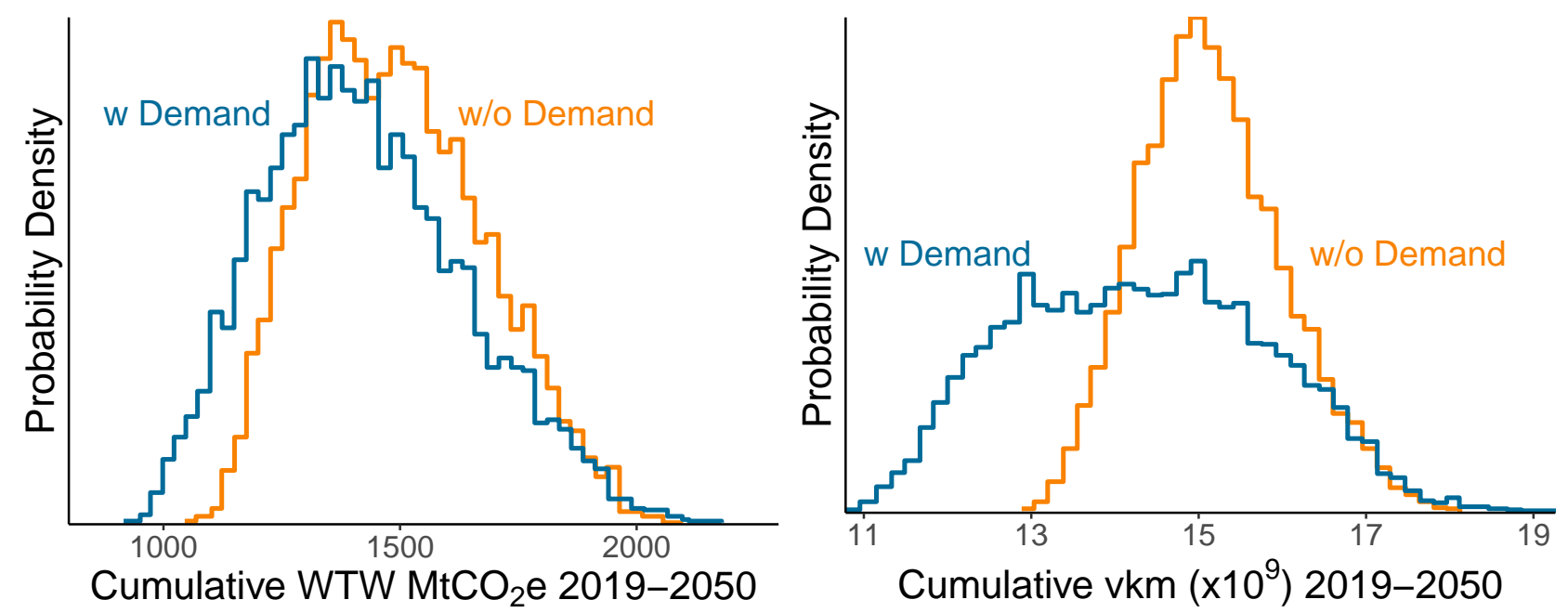

Figure 12: Probability density of cumulative Well-to-Wheel (left) and vehicle kilometres (right)years 2019-2050 split by model runs with (blue) and without (orange) changes in per capita demand. Histograms without demand are the same as those presented in figures 6 and 9 respectively.

Figure 13 and table ?? present the Sobol indices for each variable including travel demand. This shows the year that internal combustion engine vehicles are banned remains the most important variable at explaining future variance in $\mathrm{CO}_{2}$ emissions and that limiting increases in vehicle size and power remains important. However, limiting travel demand can play an equally important role at reducing emissions, energy use and vehicle kilometres since it has the potential to act immediately to limit cumulative travel. Any efforts to avoid travel demand returning to business-as-usual will have significant effects at reducing future transport emissions.

An additional motivation for reducing demand are the serious problems associated with the sourcing and end-of-life treatment of battery materials for electric vehicles. For example, a future with high EV sales could require the production of 7 million vehicles by 2030 and 51 million by 2050 . Each EV on average will have a $\approx 400 \mathrm{~kg}$ battery, necessitating the extraction and eventual disposal of some 22 million tonnes of battery materials by 2050, rich in critical and difficult to source and recycle elements such as lithium, nickel and cobalt (IEA, 2019).

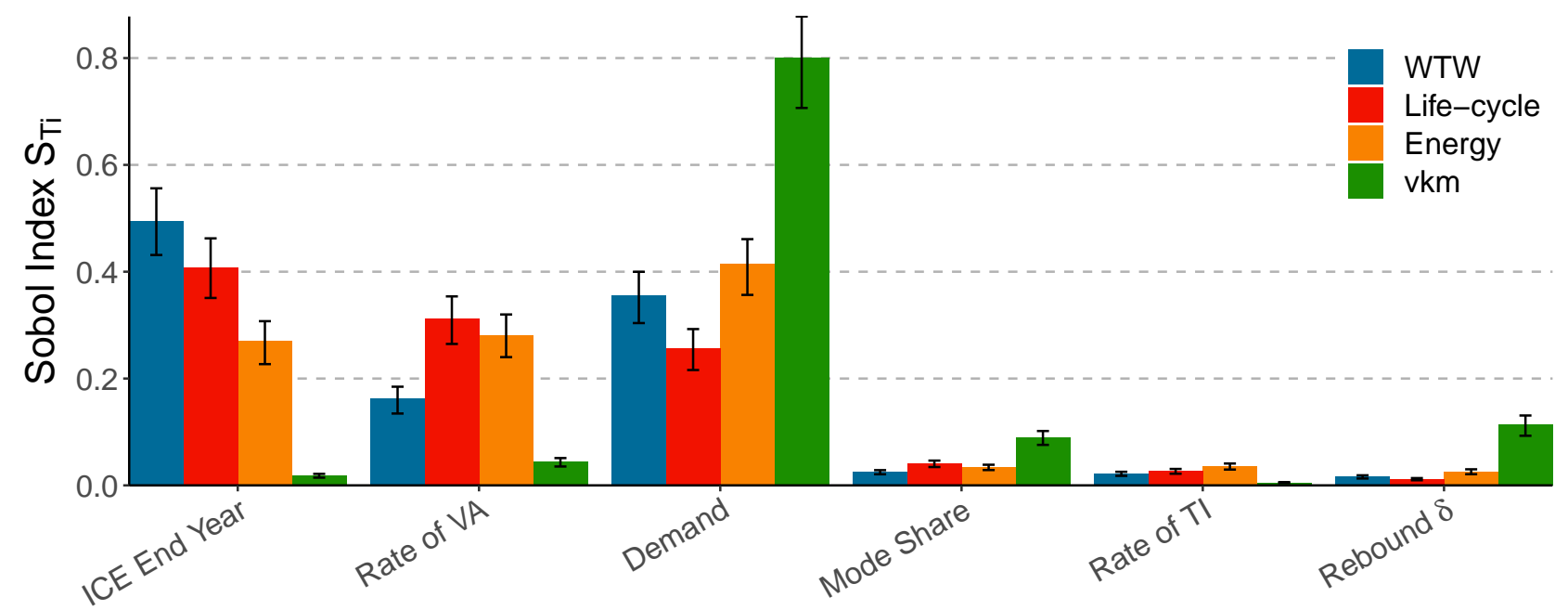

Figure 13: Sobol indices $S_{T i}$ for each input variable on cumulative WTW and life-cycle $\mathrm{CO}_{2}$ emissions, final energy use and vehicle kilometres 2019-2050 including changes in underlying travel demand. 


\section{Discussion and Policy Considerations}

Having determined the relative importance of variables, this section focuses on the implications of the results and the challenges and opportunities for policy measures to reduce future transport emissions.

Future levels of carbon emissions produced by the transport sector are highly uncertain and difficult to predict. This study estimates a range of possible futures for the British passenger car fleet using a set of plausible ranges for input variables.

Excluding lasting changes in demand, the share of ULEVs and the rate of change in vehicle size and power together account for over $80 \%$ of the uncertainty of future cumulative emissions in both the WTW and life-cycle calculations. The plausible futures investigated in this paper suggest these two variables must be a priority for transport policy makers going forward.

The uptake of ULEV sales holds, by some distance, the most importance in limiting future emissions from the British passenger vehicle stock. Recent UK government announcements to ban the sales of ICE engines from 2035 are therefore welcome. It is important for measures to be put in place to attain this goal and accelerate this transition further. Furthermore, it makes little difference whether the market adopts BEVs or PHEVs under current projections of grid carbon intensities.

The leading market for electric vehicles in terms of market share globally is Norway. The share of EVs jumped from $5.8 \%$ in 2013 (ICCT, 2019) to $64.4 \%$ in January 2020, a rate of 8.4\% market share/year. Achieving 100\% ULEV market share in the UK by 2035 would require a rate of $6.7 \%$ market share/year, so is not outside the realms of possibility. To date, no vehicle market has achieved a market share of ULEVs higher than Norway and there may be particular challenges attaining full market coverage. Similarly, Norway offers significantly larger government subsidies for ULEVs than the UK (Mersky et al. 2016); without these, the uptake of ULEVs in the British market may proceed at a slower pace. In contrast, the increasing market maturity and availability of ULEV models have the potential to increase sales (IEA, 2019).

The second most important variable, in both the WTW and life-cycle $\mathrm{CO}_{2}$ calculations, is vehicle size and power, explaining $21 \%$ and $36 \%$ of future variance respectively. Vehicle size and power are equally influential for future final energy demand. Current government policy only tackles vehicle size and power indirectly, via registration taxes and fuel economy standards; these act upon vehicle fuel efficiency, rather than vehicle attributes directly. This firstly means that if these policy instruments are not sufficiently stringent, then potential emissions savings will continue to be offset by increasing vehicle size and power. Secondly, it means that the life-cycle impacts of increasing vehicle size and power are omitted from policy coverage. Since vehicle size and power increases are the second most important variable at defining future cumulative emissions, addressing vehicle attribute changes directly has the potential to significantly reduce emissions. The large impact that VA has on life-cycle $\mathrm{CO}_{2}$ emissions could be further mitigated by lowering the carbon intensity of manufacture, which was conservatively assumed to be constant in this analysis.

It is recommended that life-cycle emissions be considered in the formulation of future policy for passenger vehicles. Currently, UK climate change policy is mostly made using WTW emissions criteria (CCC, 2019). The results show that switching to a life-cycle emissions basis does not change the relative importance of the variables, with the ICE end year still dominating. However, using life-cycle emissions amplifies the importance of policies targeting vehicle size and power, as larger vehicles have higher embodied emissions. Beyond emissions, the sourcing and end-of-life treatment of battery materials for electric vehicles poses serious challenges. Policy evidence and instruments which account of life-cycle impacts are therefore clearly needed.

In addition to highlighting the most important variables to direct industry and policy ef- 
forts towards, the results also point out lower priority variables. In particular, it is suggested that directing extensive debate and policy efforts towards topics such as the merits of hybrids over traditional internal combustion engines, or battery electric vehicles vs. PHEVs and their utilisation ratio, are not of primary importance. Perhaps surprisingly, incremental technical efficiency improvements are found to be a variable of low importance, such is the emissions intensity improvement from switching to an electric vehicle.

The carbon intensity of the British grid is projected to continue to fall substantially due to the rapid phase-out of coal fired generation and the uptake of renewables. However, the difference between attaining a grid carbon intensity in line with the relatively pessimistic National Grid 'Consumer Evolution' scenario, and meeting the more aggressive 'Two degrees' scenario, has little impact on carbon emissions. This is because the carbon intensity of electricity from the national grid is projected to decrease substantially in coming years, even under relatively pessimistic scenarios (National Grid ESO, 2019). A future low carbon electricity grid is physically possible and compatible with high electric vehicle uptake. According to National Grid, electric vehicles and smart charging can facilitate the integration of renewable electricity generation. Furthermore, the additional peak electricity demand in a high EV uptake scenario would be in the order of 5 GW, just $8 \%$ higher than today's levels (National Grid, 2017).

The rebound effect is a relatively unimportant factor for future $\mathrm{CO}_{2}$ emissions and energy use from transport. However, the difference between assuming $\delta_{\text {Rebound }}=0.046$ and $\delta_{\text {Rebound }}=0.3$ can have important effects on projections of travel demand. It is therefore crucial to maintain accurate estimates of the rebound effect in numerical models used for policy guidance. The effects of the rebound effect on travel demand could be offset with road pricing measures.

Finally, current government projections assume bus travel will remain constant at 2020 levels to 2050, and that rail passenger miles travelled will increase by $60 \%$ from 2019 levels by 2050 (DfT, 2020). However, total transport demand is also projected to increase, meaning the latter is minor in terms of modal shift from car travel. This means modal shift is a relatively unimportant variable for reducing $\mathrm{CO}_{2}$ emissions, if the frequency and distance of current travel demand remains unchanged. Meaningfully reducing vehicle kilometres by car therefore requires a fundamental change relying on fewer long distance trips. 


\section{Supporting Information}

\section{Regression Results}

Data on fuel economy/energy efficiency of BEVs and PHEVs used to calculate the sensitivities of efficiency and weight to vehicle attributes are sourced from (EPA, 2020). These are matched with vehicle dimensions and weight data from online databases (McGregor, 2017). ICE and HEV coefficients from Craglia and Cullen (2019).

\begin{tabular}{|c|c|c|c|c|c|}
\hline $\mathrm{MJ} / \mathbf{k m}$ & \multicolumn{5}{|c|}{ Powertrain $f$} \\
\hline & ICE & $\mathrm{HEV}$ & $\mathrm{PHEV}_{\mathrm{ICE}}$ & $\mathrm{PHEV}_{\mathrm{EV}}$ & $\mathrm{BEV}$ \\
\hline$\beta_{\text {Power }}(\mathrm{MJ} / \mathrm{km} \mathrm{kW}) \times 10^{-} 3$ & $8.642^{* * *}$ & $6.637^{* * *}$ & $5.375^{* * *}$ & $2.181^{* * *}$ & $0.155^{*}$ \\
\hline$\beta_{\text {Area }}\left(\mathrm{MJ} / \mathrm{km} \mathrm{m}^{2}\right)$ & $0.653^{* * *}$ & $0.632^{* * *}$ & $0.571^{* * *}$ & $0.293^{* * *}$ & $0.221^{* * *}$ \\
\hline $\mathrm{R}^{2}$ & 0.648 & 0.872 & 0.785 & 0.727 & 0.351 \\
\hline Observations & 94673 & 852 & 122 & 122 & 118 \\
\hline
\end{tabular}

Table 7: Sensitivity coefficients between vehicle attributes (frontal area and power) and vehicle energy efficiency. Statistical significance: . $\mathrm{p}<0.1,{ }^{*} \mathrm{p}<0.05,{ }^{* *} \mathrm{p}<0.01,{ }^{* * *} \mathrm{p}<0.001$

\begin{tabular}{l|rrrr} 
Vehicle Weight & \multicolumn{3}{|c}{ Powertrain $f$} \\
\hline & ICE & HEV & PHEV & BEV \\
\hline$\phi_{\text {Power }}(\mathrm{kg} / \mathrm{kW})$ & $2.647^{* * *}$ & $3.426^{* * *}$ & $1.887^{* * *}$ & $1.169^{* * *}$ \\
$\phi_{\text {Area }}\left(\mathrm{kg} / \mathrm{m}^{2}\right)$ & $846.7^{* * *}$ & $859.4^{* * *}$ & $581.4^{* * *}$ & $670.2^{* * *}$ \\
\hline $\mathrm{R}^{2}$ & 0.835 & 0.902 & 0.835 & 0.625 \\
Observations & 94673 & 852 & 122 & 118
\end{tabular}

Table 8: Sensitivity coefficients between vehicle attributes (frontal area and power) and vehicle weight. Statistical significance: . $\mathrm{p}<0.1,{ }^{*} \mathrm{p}<0.05,{ }^{* *} \mathrm{p}<0.01,{ }^{* * *} \mathrm{p}<0.001$

\begin{tabular}{l|rr} 
Battery Weight & Powertrain $f$ & \\
\hline & BEV & PHEV \\
\hline$\lambda_{\text {Power }}(\mathrm{kg} / \mathrm{kW})$ & $1.079(0.08)^{* * *}$ & $0.039(0.01)^{* * *}$ \\
$\lambda_{\text {Area }}\left(\mathrm{kg} / \mathrm{m}^{2}\right)$ & $98.89(52.3)$. & $7.09(3.09)^{*}$ \\
\hline $\mathrm{R}^{2}$ & 0.745 & 0.277 \\
Observations & 118 & 102
\end{tabular}

Table 9: Sensitivity coefficients between vehicle attributes (frontal area and power) and battery weight. Statistical significance: . $\mathrm{p}<0.1,{ }^{*} \mathrm{p}<0.05,{ }^{* *} \mathrm{p}<0.01,{ }^{* * *} \mathrm{p}<0.001$ 


\section{LightWeighting}

\begin{tabular}{l|lll} 
& Estimate & SE & \\
\hline (Intercept) & -596.888 & 6.43475 & $* * *$ \\
Year2002 & 1.9211 & 3.84033 & \\
Year2003 & -17.6503 & 3.97064 & $* * *$ \\
Year2004 & -12.8253 & 3.91869 & $* *$ \\
Year2005 & -11.2795 & 3.81559 & $* *$ \\
Year2006 & -4.33146 & 3.92685 & \\
Year2007 & -4.14075 & 3.96475 & \\
Year2008 & -12.164 & 3.97037 & $* *$ \\
Year2009 & -13.7359 & 3.84719 & $* * *$ \\
Year2010 & -7.90003 & 3.78103 & $*$ \\
Year2011 & -7.77708 & 3.85892 & $*$ \\
Year2012 & -24.3646 & 3.78738 & $* * *$ \\
Year2013 & -31.5203 & 3.76808 & $* * *$ \\
Year2014 & -51.7437 & 3.75628 & $* * *$ \\
Year2015 & -63.4783 & 3.62143 & $* * *$ \\
Year2016 & -90.7678 & 3.73732 & $* * *$ \\
Year2017 & -91.674 & 3.73152 & $* * *$ \\
Year2018 & -105.288 & 3.88067 & $* * *$ \\
kw & 2.64712 & 0.01077 & $* * *$ \\
Area & 846.7431 & 2.28661 & $* * *$ \\
\hline R 2 & 0.708 & & \\
Observations & 94673 & & \\
\hline
\end{tabular}

Table 10: Regression of vehicle weight vs. engine power $(\mathrm{kw})$ and frontal area with year dummy variables. Statistical significance: . $\mathrm{p}<0.1,{ }^{*} \mathrm{p}<0.05,{ }^{* *} \mathrm{p}<0.01,{ }^{* * *} \mathrm{p}<0.001$ 


\section{Data}

The main sources of data used to initialize the stock model are presented in table 11 .

\begin{tabular}{|c|c|}
\hline Parameter & Source \\
\hline Registered vehicles, years 2011-2018 & DfT $(2019 \mathrm{c})$ \\
\hline Number of newly registered vehicles & $\overline{\mathrm{DfT}}(\overline{\overline{2019 d}})$ \\
\hline Vehicle Occupancy & $\overline{\mathrm{DfT}}(\overline{2019 \mathrm{a}})$ \\
\hline New car average power and frontal area & Craglia and Cullen 2019) \\
\hline New car average real-world fuel efficiency & Craglia and Cullen $(\overline{\overline{2019}})$ \\
\hline BEV, PHEV new car average WLTP fuel efficiency & $\overline{\mathrm{VCA}}(2019)$ \\
\hline British passenger transport by mode $2002-2018$ & $\overline{\mathrm{DfT}}(2019 \mathrm{~b})$ \\
\hline Electricity and Fuels GHG Conversion factors & BEIS (2019) \\
\hline Fuel consumption information for EVs and PHEVs & EPA $(2020)$ \\
\hline
\end{tabular}

Table 11: Sources of data

\section{Powertrain emissions}

The table below shows the base level of emissions intensity of vehicles in the year 2018. PHEVs are split by $50 \%$ utilisation factor in the upper bound and $90 \%$ utilisation in the lower bound. $\mathrm{MJ} / \mathrm{km}$ is the average energy efficiency of each powertrain, for PHEVs this is a compound of electricity and fuel. $\mathrm{gCO}_{2} / \mathrm{MJ}$ is the average emissions produced for each $\mathrm{MJ}$ of fuel (again a compound for PHEVs based on the utilisation factor assumed). The carbon intensity of electricity in 2018 was $248 \mathrm{gCO}_{2} / \mathrm{kWh}$.

\begin{tabular}{l|cllll} 
Data & Year & $\mathrm{MY}$ & $\mathrm{MJ} / \mathrm{km}$ & $\mathrm{gCO}_{2} / \mathrm{MJ}$ & $\mathrm{gCO}_{2} \mathrm{~km}$ \\
\hline $\mathrm{ICE}$ & 2018 & 2018 & 2.34 & 72.99 & 170.79 \\
$\mathrm{HEV}$ & 2018 & 2018 & 1.75 & 72.99 & 127.73 \\
$\mathrm{BEV}$ & 2018 & 2018 & 0.72 & 68.89 & 49.6 \\
PHEV (90\% U) & 2018 & 2018 & 0.88 & 69.3 & 61.12 \\
PHEV (50\% U) & 2018 & 2018 & 1.53 & 70.94 & 108.54
\end{tabular}

\section{Acknowledgements}

This work was funded under EPSRC grant numbers: EP/M506485/1 and EP/M508007/1.

\section{References}

ANL (2019). GREET Fuel Cycle Model. Technical report, Argonne National Laboratories.

Bandivadekar, A., Cheah, L., Evans, C., Groode, T., Heywood, J., Kasseris, E., Kromer, M., and Weiss, M. (2008). Reducing the fuel use and greenhouse gas emissions of the US vehicle fleet. Energy Policy, 36(7):2754-2760.

Baptista, P. C., Silva, C. M., Farias, T. L., and Heywood, J. B. (2012). Energy and environmental impacts of alternative pathways for the Portuguese road transportation sector. Energy Policy, 51:802-815.

Bastani, P., Heywood, J. B., and Hope, C. (2012). The effect of uncertainty on US transportrelated GHG emissions and fuel consumption out to 2050. Transportation Research Part A: Policy and Practice, 46(3):517-548. 
BEIS (2019). UK Government GHG Conversion Factors for Company Reporting 2002-2019.

Berman, B. (2020). Daimler ends hydrogen car development because it's too costly.

Bodek, K. and Heywood, J. (2008). Europe's Evolving Passenger Vehicle Fleet : Fuel Use and GHG Emissions Scenarios through 2035. MIT Laboratory for Energy and the Environment, (March):78.

Brand, C. (2010). UK Transport Carbon Model Reference Guide Working Paper. UKERC, (January).

Brand, C. (2016). Beyond 'Dieselgate': Implications of unaccounted and future air pollutant emissions and energy use for cars in the United Kingdom. Energy Policy, 97(X):1-12.

Brand, C., Anable, J., and Morton, C. (2019). Lifestyle, efficiency and limits: modelling transport energy and emissions using a socio-technical approach. Energy Efficiency, 12(1):187-207.

Brand, C., Anable, J., and Tran, M. (2013). Accelerating the transformation to a low carbon passenger transport system: The role of car purchase taxes, feebates, road taxes and scrappage incentives in the UK. Transportation Research Part A: Policy and Practice, 49:132-148.

Campbell, P. (2020). UK plans to ban sale of all polluting cars by 2035.

CCC (2015). Sectoral scenarios for the fifth carbon budget Figure B5.7. Technical report, UK Committee on Climate Change.

CCC (2018). Hydrogen in a low-carbon economy. Technical Report November.

CCC (2019). Net Zero: The UK's contribution to stopping global warming. Committee on Climate Change, (May):275.

Cheah, L., Bandivadekar, A., Bodek, K., Kasseris, E., and Heywood, J. B. (2009). The Tradeoff between Automobile Acceleration Performance, Weight, and Fuel Consumption. SAE Int. J. Fuels Lubr., pages 771-777.

Craglia, M. and Cullen, J. (2019). Do technical improvements lead to real efficiency gains? Disaggregating changes in transport energy intensity. Energy Policy, 134(April):110991.

Craglia, M. and Cullen, J. M. (2020). Do vehicle efficiency improvements lead to energy savings? The Rebound Effect in Great Britain. Energy Economics, 88(104775).

Daly, H. E. and O Gallachoir, B. P. (2011). Modelling future private car energy demand in Ireland. Energy Policy, 39(12):7815-7824.

DfT (2018). Road Traffic Forecasts 2018. Technical Report July, UK Department for Transport.

DfT (2019a). Table NTS0905 Car/van occupancy and lone drive rate by trip purpose.

DfT (2019b). Table TSGB0101: Passenger transport by mode from 1952.

DfT (2019c). Table Veh0124: Licensed cars by make, model and year of first registration.

DfT (2019d). Table Veh0153: Vehicles registered or the first time by tax class.

DfT (2020). Decarbonising transport: Setting the Challenge. Technical report, UK Department for Transport. 
Dimitropoulos, A., Oueslati, W., and Sintek, C. (2016). The Rebound Effect in Road Transport. OECD Environment Working Papers.

Dunant, C., Shah, T., Drewniok, M., Craglia, M., and Cullen, J. (2020). A new method to estimate the life-time of long life product categories. Journal of Industrial Ecology, ((Under review)).

EPA (2020). Fuel economy database.

Garcia, R. and Freire, F. (2017). A review of fleet-based life-cycle approaches focusing on energy and environmental impacts of vehicles. Renewable and Sustainable Energy Reviews, 79(April):935-945.

Garcia, R., Gregory, J., and Freire, F. (2015). Dynamic fleet-based life-cycle greenhouse gas assessment of the introduction of electric vehicles in the Portuguese light-duty fleet. International Journal of Life Cycle Assessment, 20(9):1287-1299.

González Palencia, J. C., Furubayashi, T., and Nakata, T. (2012). Energy use and CO2 emissions reduction potential in passenger car fleet using zero emission vehicles and lightweight materials. Energy, 48(1):548-565.

Goodwin, P., Dargay, J., and Hanly, M. (2004). Elasticities of road traffic and fuel consumption with respect to price and income: A review. Transport Reviews, 24(3):275-292.

Hoekstra, A. (2019). The Underestimated Potential of Battery Electric Vehicles to Reduce Emissions. Joule, 3(6):1412-1414.

Homma, T. and Saltelli, A. (1996). Importance measures in global sensitivity analysis of nonlinear models. Reliability Engineering and System Safety, 52(1):1-17.

Hughes, J. E., Knittel, C. R., and Sperling, D. (2008). Evidence of a shift in the short-run price elasticity of gasoline demand. The Energy Journal, 29(1):113-134.

ICCT (2019). European Vehicle Market Statistics. EU Pocketbook.

IEA (2018). World Energy Outlook 2018. World Energy Outlook. OECD.

IEA (2019). Global EV Outlook 2019. Technical report, International Energy Agency.

Kagawa, S., Hubacek, K., Nansai, K., Kataoka, M., Managi, S., Suh, S., and Kudoh, Y. (2013). Better cars or older cars?: Assessing CO2 emission reduction potential of passenger vehicle replacement programs. Global Environmental Change, 23(6):1807-1818.

Knobloch, F., Hanssen, S. V., Lam, A., Pollitt, H., Salas, P., Chewpreecha, U., Huijbregts, M. A. J., and Mercure, J.-f. (2020). Net emission reductions from electric cars and heat pumps in 59 world regions over time. Nature Sustainability.

Martin, N. P. D., Bishop, J. D. K., and Boies, A. M. (2017). How Well Do We Know the Future of CO 2 Emissions? Projecting Fleet Emissions from Light Duty Vehicle Technology Drivers. Environmental Science $\&$ Technology, page acs.est.6b04746.

Martin, N. P. D., Bishop, J. D. K., Choudhary, R., and Boies, A. M. (2015). Can UK passenger vehicles be designed to meet 2020 emissions targets? A novel methodology to forecast fuel consumption with uncertainty analysis. Applied Energy, 157:929-939. 
McCollum, D. and Yang, C. (2009). Achieving deep reductions in US transport greenhouse gas emissions: Scenario analysis and policy implications. Energy Policy, 37(12):5580-5596.

McGregor, Z. (2017). www.carfolio.com.

Melaina, M. and Webster, K. (2011). Role of fuel carbon intensity in achieving 2050 greenhouse gas reduction goals within the light-duty vehicle sector. Environmental Science and Technology, 45(9):3865-3871.

Mersky, A. C., Sprei, F., Samaras, C., and Qian, Z. S. (2016). Effectiveness of incentives on electric vehicle adoption in Norway. Transportation Research Part D: Transport and Environment, 46:56-68.

Modaresi, R., Pauliuk, S., Løvik, A. N., and Müller, D. B. (2014). Global carbon benefits of material substitution in passenger cars until 2050 and the impact on the steel and aluminum industries. Environmental Science and Technology, 48(18):10776-10784.

Monod, H., Naud, C., and Makowski, D. (2006). Uncertainty and sensitivity analysis for crop models in Working with Dynamic Crop Models: Evaluation, Analysis, Parameterization, and Applications. Elsevier, 1st edition.

National Grid (2017). Our energy insights. Technical Report August, National Grid.

National Grid ESO (2019). Future Energy Scenarios 2019. Future Energy Scenarios, (July):162.

Nocera, S. and Cavallaro, F. (2016). The competitiveness of alternative transport fuels for CO2emissions. Transport Policy, 50:1-14.

NTS (2019). UK National Travel Survey, 2002-2016.

Onat, N. C., Kucukvar, M., and Tatari, O. (2016). Uncertainty-embedded dynamic life cycle sustainability assessment framework: An ex-ante perspective on the impacts of alternative vehicle options. Energy, 112:715-728.

ONS (2019). UK National population projections: 2018-based.

ONS (2020). Coronavirus, the UK economy and society, faster indicators: 7 May 2020.

Owen, A. B. (2016). Sobol Indices: an Introduction and Some Recent Results.

Paoli, L. and Cullen, J. (2019). Technical limits for energy conversion efficiency. Energy, page 116228.

Pauliuk, S., Dhaniati, N. M. A., and Müller, D. B. (2012). Reconciling sectoral abatement strategies with global climate targets: The case of the chinese passenger vehicle fleet. Environmental Science and Technology, 46(1):140-147.

Pianosi, F., Beven, K., Freer, J., Hall, J. W., Rougier, J., Stephenson, D. B., and Wagener, T. (2016). Sensitivity analysis of environmental models: A systematic review with practical workflow. Environmental Modelling and Software, 79:214-232.

Quaglietta, E. and Punzo, V. (2013). Supporting the design of railway systems by means of a Sobol variance-based sensitivity analysis. Transportation Research Part C: Emerging Technologies, 34:38-54. 
Reichmuth, D. S., Lutz, A. E., Manley, D. K., and Keller, J. O. (2013). Comparison of the technical potential for hydrogen, battery electric, and conventional light-duty vehicles to reduce greenhouse gas emissions and petroleum consumption in the United States. International Journal of Hydrogen Energy, 38(2):1200-1208.

Romanowicz, T. M. and Owsiński, J. W. (1988). On dynamic modeling of car populations. Part I. Technological Forecasting and Social Change, 34(1):81-94.

Saltelli, A. and Annoni, P. (2010). How to avoid a perfunctory sensitivity analysis. Environmental Modelling and Software, 25(12):1508-1517.

Saltelli, A., Annoni, P., Azzini, I., Campolongo, F., Ratto, M., and Tarantola, S. (2010). Variance based sensitivity analysis of model output. Design and estimator for the total sensitivity index. Computer Physics Communications, 181(2):259-270.

Serrenho, A. C., Norman, J. B., and Allwood, J. M. (2017). The impact of reducing car weight on global emissions: the future fleet in Great Britain. Philosophical Transactions of the Royal Society A: Mathematical, Physical and Engineering Sciences.

Singh, B. and Strømman, A. H. (2013). Environmental assessment of electrification of road transport in Norway: Scenarios and impacts. Transportation Research Part D: Transport and Environment, 25(2013):106-111.

Smith, C. J., Forster, P. M., Allen, M., Fuglestvedt, J., Millar, R. J., Rogelj, J., and Zickfeld, K. (2019). Current fossil fuel infrastructure does not yet commit us to $1.5 \mathrm{C}$ warming. Nature Communications, 10(1):1-10.

Sobol, I. M. (2001). Global sensitivity indices for nonlinear mathematical models and their Monte Carlo estimates. Mathematics and Computers in Simulation, 55(1-3):271-280.

Top Gear (2017). Volkswagen XL1 Review.

VCA (2019). Car fuel and emissions information.

Wadud, Z., MacKenzie, D., and Leiby, P. (2016). Help or hindrance? The travel, energy and carbon impacts of highly automated vehicles. Transportation Research Part A: Policy and Practice, 86:1-18.

Wei, T. (2013). A review of sensitivity analysis methods in building energy analysis. Renewable and Sustainable Energy Reviews, 20:411-419.

Zachariadis, T., Samaras, Z., and Zierock, K. H. (1995). Dynamic modeling of vehicle populations: An engineering approach for emissions calculations. Technological Forecasting and Social Change, 50(2):135-149. 